\title{
Improving Vehicle Ride and Handling Using LQG CNF Fusion Control Strategy for an Active Antiroll Bar System
}

\author{
N. Zulkarnain, ${ }^{1}$ H. Zamzuri, ${ }^{1}$ Y. M. Sam, ${ }^{2}$ S. A. Mazlan, ${ }^{3}$ and S. M. H. F. Zainal ${ }^{1}$ \\ ${ }^{1}$ Vehicle System Engineering Research Laboratory, Universiti Teknologi Malaysia, Jalan Semarak, 54100 Kuala Lumpur, Malaysia \\ ${ }^{2}$ Faculty of Electrical Engineering, Universiti Teknologi Malaysia, 81310 Skudai, Johor, Malaysia \\ ${ }^{3}$ Malaysia-Japan International Institute of Technology, Universiti Teknologi Malaysia, Jalan Semarak, 54100 Kuala Lumpur, Malaysia
}

Correspondence should be addressed to N. Zulkarnain; noraishikin2@live.utm.my

Received 7 May 2014; Revised 6 August 2014; Accepted 11 August 2014; Published 23 October 2014

Academic Editor: Manuel Ruiz Galán

Copyright (c) 2014 N. Zulkarnain et al. This is an open access article distributed under the Creative Commons Attribution License, which permits unrestricted use, distribution, and reproduction in any medium, provided the original work is properly cited.

\begin{abstract}
This paper analyses a comparison of performance for an active antiroll bar (ARB) system using two types of control strategy. First of all, the LQG control strategy is investigated and then a novel LQG CNF fusion control method is developed to improve the performances on vehicle ride and handling for an active antiroll bar system. However, the ARB system has to balance the trade-off between ride and handling performance, where the CNF consists of a linear feedback law and a nonlinear feedback law. Typically, the linear feedback is designed to yield a quick response at the initial stage, while the nonlinear feedback law is used to smooth out overshoots in the system output when it approaches the target reference. The half car model is combined with a linear single track model with roll dynamics which are used for the analysis and simulation of ride and handling. The performances of the control strategies are compared and the simulation results show the LQG CNF fusion improves the performances in vehicle ride and handling.
\end{abstract}

\section{Introduction}

The automobile is composed of many systems. One of these is the antiroll bar system. The main functions of the automotive antiroll bar system are to provide vehicle support, stability, and directional control during handling maneuvers and to provide effective isolation from road disturbances. Besides that, antiroll bar is a suspension element that is used at the front, rear, or at both ends of a car that reduces body roll by resisting any unequal vertical motion between the pair of wheels to which it is connected [1]. Figure 1 shows the illustration of antiroll bar that connects with left and right wheels.

A ground vehicle design typically represents a trade-off between ride comfort performance and also safety criteria. Ride and handling are one of the key attributes in the vehicle, which communicate directly to the customer perception of satisfaction [2]. The ride comfort is defined as the level of comfort experienced by the passenger in a form of numerical values, that is, weighted root mean square (RMS) of acceleration $[3,4]$. Meanwhile, handling performance is defined by quality of handling, which relates to subjective feelings of human driver and also objective measurement of the vehicle characteristics. Unfortunately, there are trade-offs between these attributes and it is a challenge for automotive engineer to make a vehicle with a good ride and a good handling at the same time. Many studies have been done on active system to tackle this trade-off. Some prefer to develop active suspension while some others prefer to focus on advancing the antiroll bar. However, from the manufacturer's point of view, cost is the key factor. In this factor, antiroll bar system has the advantage since it can provide solution to ride and handling trade-off with lower cost compared to active suspension.

Basically, the passive antiroll bar (ARB) has the advantages to reduce the body roll acceleration and roll angle during single wheel lifting and cornering maneuver. By reducing body roll motion, the driving safety and handling stability will be highly improved [5]. However, the passive antiroll bar also has disadvantages. During cornering maneuver, antiroll bar will transfer vertical forces of one side of the suspension to the other side and therefore create moments against lateral force. Unfortunately, during straight line driving, lateral forces 


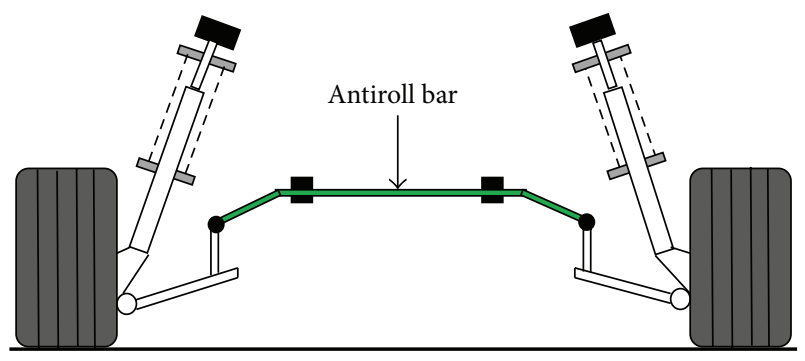

FIGURE 1: Schematic presentation of an antiroll in action [1].

induced by road irregularities will also get the same effect as the one induced by cornering maneuver and therefore deteriorate ride comfort. In a conventional passive suspension system, which comprises springs and dampers, a trade-off is needed to resolve the conflicted requirements of ride comfort and better handling performance. The reason is that stiff suspension is required to support the weight of the vehicle and to follow the track. On the other hand, soft suspension is needed to isolate the disturbance from the road. Hence there exists a significantly growing interest in the design and control of active ARB suspension systems from automotive engineers and researchers in the past three decades [4]. For that reason, an active antiroll bar is developed to improve the disadvantages of passive antiroll bar while at the same time augmenting ride comfort and handling stability.

A variety of solutions have been studied to compromise the trade-off between ride and handling. These solutions include passive suspension systems, semiactive suspension systems, active suspension systems, and antiroll bar. But antiroll bar recently has become very popular among researchers to tackle the issues of trade-off between ride and handling $[6,7]$. Cronjé and Els had studied the effect of the active antiroll bar on ride comfort and handling of an off-road vehicle [8]. They also analysed the use of an active antiroll bar as a means of improving the handling of an off-road vehicle without sacrificing the ride comfort.

In a ground vehicle, ride comfort and handling stability conflict with each other making it hard for a vehicle suspension system to pursue them simultaneously. However, Danesin et al. have successfully designed an active roll control system to increase handling and ride comfort [9]. In order to improve the vehicle performance relating in this area, a lot of control schemes have been proposed in the framework of the computer controlled suspension system such as active or semiactive suspension system $[4,5]$. Some studies investigating the use of preview control have predicted potential benefits.

Moreover, a design strategy for the control system of the electric power steering (EPS) in consideration of the active ARB to avoid side effects to the steering system by the reaction force of the front tire due to roll stiffness control for the active ARB was proposed by Yamamoto and Nishimura [10]. Gain-scheduled (GS) control is used in designing the EPS method to assist properly driver in the steering according to the vehicle speed and realize the hydraulic power steering (HPS) like steering feeling. The active ARB is obtained using the linear quadratic control theory in order to balance competing goals for the roll reduction on cornering and the suppression of the rolling vibration on the rough road [10]. An active ARB has an actuator which can actively generate the torque at the centre of an ARB. It is verified that the control system designed can settle the rolling vibration on the rough road more quickly than the vehicle model of a normal suspension while reducing the steady roll angle during cornering. Besides, an electric ARB system has been developed as a technology for controlling vehicle roll angle performance by $[11,12]$. Various sensors that detect the vehicle's running state, an active ARB that used electric motors and reduction gears to control roll, are included in the system.

However, the CNF control law so far is not yet implemented in the active ARB suspension system. This motivated us to apply the CNF control technique to improve the performances of the active ARB system as the one contribution of this study. The CNF control technique is a nonlinear method applicable to control design for the linear time-invariant systems with input saturation. The CNF control technique was proposed in [13] and was effectively implemented in $[14,15]$. There are two parts of the CNF control law such as the linear control law and the nonlinear feedback part. Such CNF control laws can significantly improve the tracking and regulating performances of the resulting closed-loop systems as the CNF control technique makes use of the advantages of the low and high damping-ratios by smoothly switching.

By using LQR, Gosselin-Brisson et al. designed an active antiroll bar using full state feedback optimal control strategy. For this control method all the state variables have to be measured by electronic sensors. A controller using four different measurements proves to be more efficient than any passive system for the vehicle studied. In selection of ARB stiffness based on selecting appropriate parameters, a graphical method has been presented. The active ARB controller has been designed by solving the ARE and a proposed simplification of the controller. The results show a superior performance in ride comfort and handling or stability for the active controller in the frequency range of interest instead of the time range [16].

In this paper, the CNF control technique is successfully applied to design the ARB controller. The designed control law is verified in simulation. The simulation results demonstrate that the improvement of the active ARB system performances using CNF with LQG compared to LQG technique. The outline of this paper is divided into four sections. In the next section, the dynamic mathematical modelling of an active ARB system is introduced. The control technique and design are applied to design the control laws for the active ARB system in Section 3. The simulation and comparison results will be presented in Section 4 and, finally, the concluding remarks are drawn.

\section{Mathematical Modeling}

The model represents the front view of a vehicle suspension system as shown in Figure 2. It includes four degrees of freedom (DOF) to model an independent suspension instead 


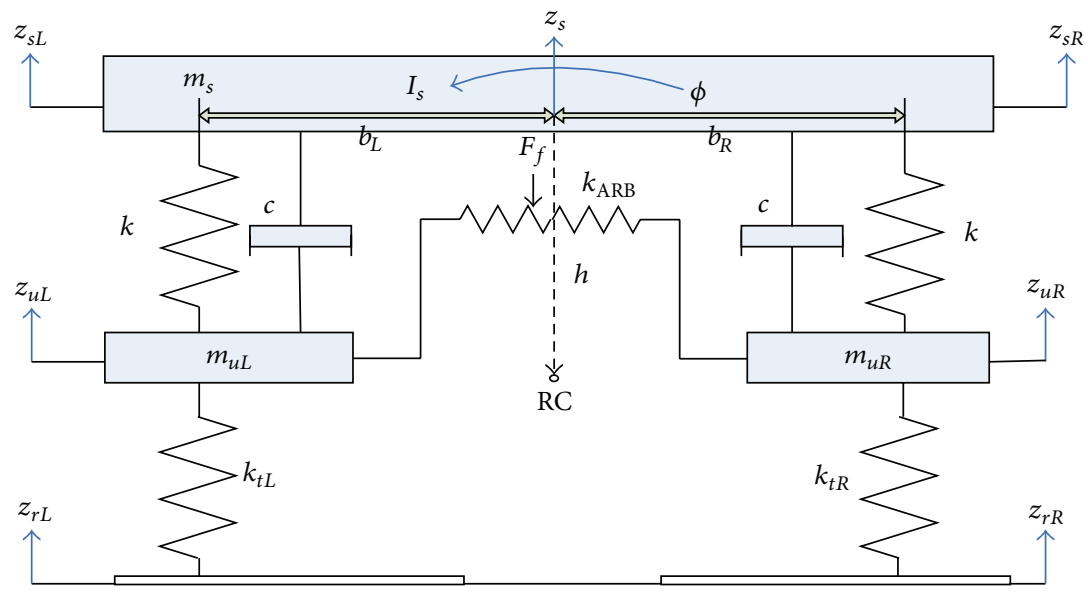

FIGURE 2: Half car model of a vehicle from front view.

of three DOF commonly used in the literature where the right and left unsprung masses are modelled by one axle only. For this work, the vehicle assumed has the same parameters on the right and left sides, which is generally true. Tire damping is ignored in this model. The sprung mass gravity centre (CG) is in the middle of the track.

During roll motion, the vehicle rotates around the sprung mass roll centre (RC). The position of this point is a function of suspension geometry, vehicle ride height and roll angle. As the sprung mass moves in roll and heave, the RC movement amplitude depends on the suspension geometry. As a general rule, large RC movement could compromise stability and should be avoided. In this study, RC position is kept and fixed to simplify the model. Parameter $h$ corresponds to the distance between the sprung mass CG and the sprung mass RC. $F_{f}$ is the force applied to control the vehicle sprung mass roll.

The vehicle suspension model is based on a half car model from front view and a single track model with roll dynamics developed from the bicycle model.

2.1. Half Car Model. The half car model explains the relation between body bounce, body roll angle, left and right wheels hop, and road excitations. Then, the equations of motions for this model are combined with the single track model with roll dynamics to design the four DOF vehicle dynamic model as follows.

Body vertical acceleration is

$$
\begin{aligned}
\ddot{z}_{s}= & -\frac{2 c \dot{z}_{s}}{m_{s}}+\frac{c \dot{z}_{u L}}{m_{s}}+\frac{c \dot{z}_{u R}}{m_{s}}+\frac{c\left(b_{L}-b_{R}\right)}{m_{s}} \dot{\phi} \\
& -\frac{2 k z_{s}}{m_{s}}+\frac{k z_{u L}}{m_{s}}+\frac{k z_{u R}}{m_{s}}-\frac{k\left(b_{L}-b_{R}\right)}{m_{s}} \phi .
\end{aligned}
$$

Left wheel vertical acceleration is

$$
\begin{aligned}
\ddot{z}_{u L}= & \frac{k z_{s}}{m_{u L}}-\frac{\left(k+k_{t L}\right)}{m_{u L}} z_{u L}+\frac{c \dot{z}_{s}}{m_{u L}}-\frac{c \dot{z}_{u L}}{m_{u L}}+\frac{k b_{L}}{m_{u L}} \phi \\
& +\frac{c b_{L}}{m_{u L}} \dot{\phi}+\frac{k_{t L}}{m_{u L}} z_{r L}+F_{L} .
\end{aligned}
$$

Right wheel vertical acceleration is

$$
\begin{aligned}
\ddot{z}_{u R}= & \frac{k z_{s}}{m_{u R}}-\frac{\left(k+k_{t R}\right)}{m_{u R}} z_{u R}+\frac{c \dot{z}_{s}}{m_{u R}}-\frac{c \dot{z}_{u R}}{m_{u R}}-\frac{k b_{R}}{m_{u R}} \phi \\
& -\frac{c b_{R}}{m_{u R}} \dot{\phi}+\frac{k_{t R}}{m_{u R}} z_{r R}-F_{R} .
\end{aligned}
$$

Roll acceleration of half car model is

$$
\begin{aligned}
\ddot{\phi}= & -\frac{\left(b_{L}-b_{R}\right) k z_{s}}{I_{s}}+\frac{\left(b_{L} k z_{u L}\right)}{I_{s}}-\frac{\left(b_{R} k z_{u R}\right)}{I_{s}}-\frac{c\left(b_{L}-b_{R}\right) \dot{z}_{s}}{I_{s}} \\
& +\frac{b_{L} c \dot{z}_{u L}}{I_{s}}-\frac{b_{R} c \dot{z}_{u R}}{I_{s}}-\frac{\left(k b_{L}^{2}+k b_{R}^{2}\right)}{I_{s}} \phi \\
& -\frac{c\left(b_{L}^{2}+b_{R}^{2}\right)}{I_{s}} \dot{\phi}+e F_{f} .
\end{aligned}
$$

2.2. The Linear Single Track Model with Roll Dynamics. The simplest vehicle model is the linear single track model, also known as the bicycle model, which is obtained by approximating the front and rear pairs of wheels as single wheels. The model is illustrated in Figure 3. Assuming that the steering angle is small, the equations of motion are given by [17]. The equations of motion are augmented by a torque balance around the $x$-axis. The equations are the following. 


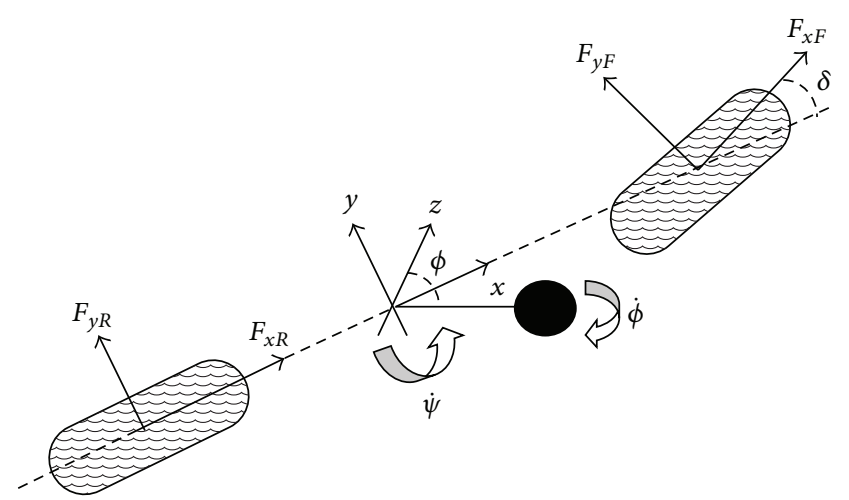

FIGURE 3: Single track model showing the combined front and rear tire forces, the steering angle, the yaw rate, and the vehicle sideslip angle [17].

\section{Lateral motion is}

$$
m\left(\dot{V}_{y}+\dot{V}_{x} \dot{\psi}\right)=F_{y F}+F_{y R}
$$

Yaw rate is

$$
\begin{gathered}
I_{z z} \ddot{\psi}=a F_{y F}-b F_{y R}, \\
I_{x x} \ddot{\phi}+C_{q} \dot{\phi}+K_{q} \phi=m h\left(\dot{V}_{y}+V_{x} \dot{\psi}\right), \\
F_{y F} \approx C_{f} \alpha_{F}, \\
F_{y R} \approx C_{r} \alpha_{R},
\end{gathered}
$$

where $F_{y F}$ and $F_{y R}$ are the combined front and rear lateral tire forces, $I_{z z}$ is the moment of inertia around the $z$-axis, $a$ and $b$ are the distances from the front and rear wheels to the centre of gravity, and $\dot{\psi}$ is the yaw rate. The slip angles of the front and rear wheels $\alpha_{F}$ and $\alpha_{R}$ can be approximated as

$$
\begin{gathered}
\alpha_{F} \approx \delta-\frac{1}{V_{x}}\left(V_{y}+\alpha \dot{\psi}\right), \\
\alpha_{R} \approx-\frac{1}{V_{x}}\left(V_{y}-b \dot{\psi}\right) .
\end{gathered}
$$

The input to the system is steering angle while the outputs of the system are lateral velocity, yaw rate, and roll rate. The transfer function equations single track model with roll dynamics system is written as follows.

Lateral acceleration is

$$
\begin{aligned}
\dot{V}_{y}= & \frac{C_{f}}{m}\left[\delta-\frac{1}{V_{x}}\left(V_{y}+a \dot{\psi}\right)\right]+\frac{C_{r}}{m}\left[-\frac{1}{V_{x}}\left(V_{y}-b \dot{\psi}\right)\right] \\
& -\dot{V}_{x} \dot{\psi} .
\end{aligned}
$$

Yaw acceleration is

$\ddot{\psi}=\frac{a C_{f}}{I_{z z}}\left[\delta-\frac{1}{V_{x}}\left(V_{y}+a \dot{\psi}\right)\right]-\frac{b C_{r}}{I_{z z}}\left[-\frac{1}{V_{x}}\left(V_{y}-b \dot{\psi}\right)\right]$.

Roll acceleration of single track model is

$$
\ddot{\phi}=\frac{m h}{I_{x x}}\left(\dot{V} y+V_{x} \dot{\psi}\right)-\frac{C_{q} \dot{\phi}}{I_{x x}}-\frac{K_{q} \phi}{I_{x x}} .
$$

2.3. Suspension Model. Three different cases are analysed which are passive suspension without ARB, passive suspension with passive $A R B$, and passive suspension with active ARB. Each case is modelled by different roll control force equations. The suspension is composed of a spring and a damper for each side of the vehicle. In this case the roll control forces are eliminated, because the only roll stiffness is provided by the suspension spring and damper [16]. Here

$$
\begin{aligned}
& F_{R}=0, \\
& F_{L}=0 .
\end{aligned}
$$

The passive suspension with the passive ARB model is representative of the most common vehicles in use today. To reduce roll motion, an ARB is added to the suspension system, increasing the total roll stiffness. The ARB is usually made of steel and acts like a spring connected to the right and left unsprung masses. The ARB force is a function of the difference between right and left suspension deflection. The force is applied by the bar on each side of the vehicle so that the left force has the same magnitude and the opposite direction as the right one. For an ARB stiffness, $k_{\mathrm{ARB}}$, the force corresponds to

$$
F_{\mathrm{ARB}}=-k_{\mathrm{ARB}}\left[\left(z_{s R}-z_{u R}\right)-\left(z_{s L}-z_{u L}\right)\right] .
$$

To model the passive ARB the forces $F_{R}$ and $F_{L}$ are given as follows:

$$
\begin{aligned}
& F_{R}=F_{\mathrm{ARB}}=-k_{\mathrm{ARB}}\left[\left(z_{s R}-z_{u R}\right)-\left(z_{s L}-z_{u L}\right)\right], \\
& F_{L}=-F_{\mathrm{ARB}}=k_{\mathrm{ARB}}\left[\left(z_{s R}-z_{u R}\right)-\left(z_{s L}-z_{u L}\right)\right] .
\end{aligned}
$$

For a passive suspension with an active ARB, generally a pneumatic or hydraulic piston [18] is used; therefore it is modelled by a controllable force. This actuator is placed in series with a stiff ARB. The force is applied with the same magnitude but in opposite directions as for the passive ARB. However, the force magnitude $F_{f}$ is calculated by the controller. As a result the forces are applied as follows:

$$
\begin{gathered}
F_{R}=F_{f}, \\
F_{L}=-F_{f} .
\end{gathered}
$$

Three different inputs can be applied to the models which are lateral force, left road motion, and right road motion. The application of left and right road motion with equal phase and amplitude results in pure vertical motion similar to the quarter model behaviour. Since this model is extensively studied in the literature, it is not detailed in this paper. On the other hand, the excitation of a single wheel gives valuable indication on how the system transfers the road perturbation from one side to the other. Since the ARB has a noticeable impact on this transfer, the first case studied is the application of a road motion input to a single wheel. As the side of the excitation application does not change the response amplitude, the input is applied at the right tire or road interface.

In ground vehicle real life use, cornering maneuvers are unavoidable. The change in trajectory is accomplished 
by creating a lateral acceleration. Since the response of the vehicle's suspension during these maneuvers is critical for stability, lateral acceleration input is the second case studied in this work.

The roll motion is caused by the vehicle's lateral acceleration, which depends on the speed and corner radius. In a manner similar to the road perturbation, the direction of the force only changes the direction of the response since the vehicle is symmetrical. For this work a right turn is simulated resulting in a left acceleration creating a force at the sprung mass CG. Since the force is applied at a distance $h$ from the rotation centre, a moment $M_{s}$ is created on the sprung mass with a magnitude given as follows:

$$
M_{s}=a_{y} m_{s} h
$$

\section{Controller Design}

3.1. Linear Quadratic Gaussian. The theory of LQG control design is well known, and it is summarised below. of

Consider the state space model of the process in the form

$$
\begin{gathered}
\dot{x}=A x+B u+\Gamma w, \\
y=C x+v,
\end{gathered}
$$

where $x \in \mathbb{R}^{n \times 1}, u \in \mathbb{R}^{m \times n}$, and $y \in \mathbb{R}^{q \times 1}$, while $w$ and $v$ are white uncorrelated process and measurement noises, respectively. In the state feedback version of the LQR, it assumes that the whole state $x$ can be measured and therefore is available for control. The state feedback controller is given by

$$
\begin{gathered}
u=-K_{r} x, \\
K_{r}=R^{-1} B^{T} P,
\end{gathered}
$$

where $K_{r}$ is gain matrix and is subject to minimize the quadratic cost function given by

$$
J=\int_{0}^{\infty}\left[x^{T}(t) Q_{r} x(t)+u^{T}(t) R_{r} u(t)\right] d t
$$

where state weighting matrix $Q$ is $n \times n$ symmetric positive definite matrix and control weighting matrix $R$ is $m \times m$ symmetric positive definite matrix.

The gain matrix $K$ is the solution matrix Riccati differential equation which is subject to given values of $A, B, C, Q$, and $R$ given by

$$
A^{T} P+P A+\dot{P}+Q=P B R_{k}^{-1} B^{T} P .
$$

If $P$ is constant then $\dot{P}=0$; the Riccati equation can be simplified to

$$
A^{T} P+P A+\dot{P}+Q-P B R_{k}^{-1} B^{T} P=0,
$$

and the solution of the gain matrix is given by

$$
K_{r}=R_{k}^{-1} B^{T} P
$$

subject to $(A, B)$ being stabilizable $R_{k}$ and $Q \geq 0$ is positive definite and positive semidefinite. $(Q, A)$ has no unobservable modes on the imaginary axis.

The LQR part guarantees the closed loop stability with appropriate choice of weighting matrices $Q$ and $R$ variables [19-21]. Since not all states parameters can be measured directly, an estimator is used for the entire state vector with respect to the plant's output. The estimator is given by

$$
\begin{aligned}
\dot{\hat{x}} & =A \widehat{x}+K_{f}(y-C \widehat{x}) \\
& =\left(A-K_{f} C\right) \hat{x}+K_{f} y,
\end{aligned}
$$

where $K_{f}$ is the estimator filter gain matrix given as

$$
K_{f}=P_{f} C^{T} R_{f}^{-1}
$$

The covariance vector $P_{f}$ of the estimated state variable is obtained by solving the algebraic Riccati equation:

$$
A P_{f}+P A^{T}-P_{f} C^{T} R_{f}^{-1} C P_{f}+B Q_{f} B^{T}=0,
$$

where $Q_{f}=E\left(\omega \omega^{T}\right)$ and $R_{f}=E\left(v v^{T}\right)$ are process and sensor noise covariances.

3.2. Composite Nonlinear Feedback Controller. Composite nonlinear control feedback is a nonlinear control technique, which contains composition of a linear feedback law and a nonlinear feedback law without any switching element. In other words, linear and nonlinear laws in this type of algorithm are working simultaneously all the time. In this method, the linear feedback objective is to get a small damping ratio for quick response and at the same time without exceeding the nature of actuator limits. Meanwhile, for nonlinear feedback, it is designed to increase the damping ratio as the system output approaches the target reference to avoid overshoot from occurrence $[19,20]$.

There are some efforts by researchers to come out more generalize version that can be implemented in higher order in multiple-input and multiple-output (MIMO) configuration since exploration of CNF for linear 2nd order system singleinput and single-output (SISO) plant as intensively discussed in literature review part. Furthermore, CNF algorithm has been enhanced to cater external disturbance as reported in several papers. Although the CNF technique is fairly mature to solve general linear system, it is not robust enough to solve parameter variation so-called uncertainties that may occur in most typical controlled plant [21].

For this classical CNF technique, controlled plant is considered without external disturbance. A linear continuous time system with actuator saturation can be expressed in general state space as follows:

$$
\begin{gathered}
\dot{x}(t)=A x(t)+B \text { sat }(u(t)), \quad x(0)=x_{0}, \\
y(t)=C_{1} x(t), \\
h(t)=C_{2} x(t),
\end{gathered}
$$

where $x \in \mathbb{R}^{n}, u \in \mathbb{R}, y \in \mathbb{R}^{p}$, and $h \in \mathbb{R}$ are the state vector, control input, measurement output, and controlled 
output vector, respectively. $A, B, C_{1}$, and $C_{2}$ are appropriate dimensional constant matrices, and sat: $\mathbb{R} \rightarrow \mathbb{R}$ represents actuator saturation which can be defined as

$$
\operatorname{sat}(u)=\operatorname{sgn}(u) \min \left\{u_{\max },|u|\right\} .
$$

In (26), $u_{\max }$ is a saturation level of actuator input. To apply the CNF, the following assumptions of system matrices are considered:

(1) $(A, B)$ is controllable (stabilizable);

(2) $\left(A, C_{1}\right)$ is observable (detectable);

(3) $\left(A, B, C_{2}\right)$ is invertible and there is no invariant zero at $s=0$.

In this research, the controller is designed based on a state feedback case $(y=x)$ where the assumption is made that all states of plant are available to measure even though in most cases observer is needed to estimate immeasurable states. There are three steps involved in the CNF design which are linear feedback design to get optimal respond, nonlinear feedback design to prevent overshoot, and finally merging both feedbacks to work together. Details of these steps are as follows.

Step 1. Design a linear feedback law:

$$
u_{L}=F x+G r,
$$

where $r$ is zero and $F$ is chosen such that $A+B F$ asymptotically stable and closed loop systems $C_{2}(s I-A-B F)^{-1}$ have certain desired properties such as low damping ratio. Selection of matrix $F$ is not unique and can be found using optimization method such $H_{2}$ and $H_{\infty}$ approaches. Besides, matrix $G$ is scalar and is given by

$$
G=-\left[C_{2}(A+B F)^{-1} B\right]^{-1} .
$$

Step 2. Design a nonlinear feedback law:

$$
u_{N}=\rho(y, r) B^{T} P\left(x-x_{e}\right),
$$

where $\rho(y, r)$ is any nonpositive local Lipschitz in $x$ such as $-\beta e^{-\alpha \alpha_{0}|y-r|}$. This function is used to change damping ratio of the closed loop system when output approaches the reference given. This nonlinear function is not unique and there are solutions to obtain optimal value of tuning the parameter that will be explained later. Matrix $P$ exists since $A+B F$ is asymptotically stable and can be obtained from following Lyapunov equation:

$$
(A+B F)^{T} P+(A+B F) P=-W .
$$

There are proper ways to find suitable value of $W$ which is positive definite as proposed by author Chen et al. [13]; however in this research, $W$ is simplifying as matrix identity. In other terms, equilibrium point $x_{e}$ is obtained by

$$
x_{e}=G_{e} r
$$

where

$$
G_{e}=-(A+B F)^{-1} B G
$$

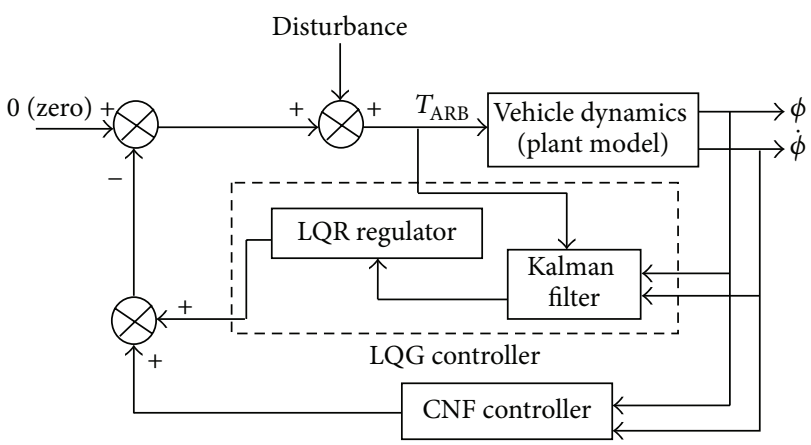

FIgURE 4: LQG CNF fusion block diagram configuration.

Step 3. Combine linear and nonlinear feedback laws:

$$
u=u_{L}+u_{N}=F x+G r+\rho(y, r) B^{T} P\left(x-x_{e}\right) .
$$

In this research, tuning parameters $\alpha$ and $\beta$ as proposed by Lan et al. [22] will be used. The first parameter $\beta$ can be found by setting a desired damping ratio of closed loop system $\xi_{\infty}$ :

$$
\dot{\tilde{x}}=\left(A+B F-\beta B B^{T} P\right) \tilde{x},
$$

whereas optimal value $\alpha$ is obtained by solving minimization of some appreciable criterions, such as integral of absolute error (IAE) and integral of time-multiplied absolute value of error (ITAE) which can be written as follows:

$$
\min _{\alpha} \int_{0}^{\infty}|e| d t \text { or } \min _{\alpha} \int_{0}^{\infty} t|e| d t,
$$

where

$$
e=y-r
$$

\section{Results and Discussions}

4.1. Design of Composite Nonlinear Feedback Based Active Antiroll Bar System. This section will present a design process of proposed control strategy. The objective of the active ARB controller is to reject disturbance and to improve the roll angle and roll rate responses as close to zero. Three types of disturbances are used in this work, which are fishhook, single sine, and speed bump.

The controllers used in this work are linear quadratic Gaussian (LQG) and composite nonlinear feedback (CNF) controller. These controllers are designed and tuned to generate the input of torque to control the active ARB system. Figure 4 shows a block diagram configuration that has been used about the combination of CNF controller, LQR controller, and Kalman filter estimator to form a compensator. This solution in designing LQG controller is based on the separation principle where the LQR controller and Kalman filter are designed independently and then combined to form the LQG compensator. A Kalman filter is a typical application and feasible estimation approach that can fuse multiple sensory measurements to provide an accurate position estimation [23]. 
TABLE 1: Numerical parameters for CNF controller.

\begin{tabular}{|c|c|c|c|c|c|c|}
\hline Parameter & & & Value & & & Description \\
\hline \multirow{2}{*}{ F } & {$[0.2398$} & -46.7288 & 49.3638 & 0.0890 & 0.3439 & \multirow{2}{*}{ Obtained based on damping ratio set as $\xi=0.67$} \\
\hline & -0.3579 & -0.6518 & 23.3893 & 0.7640 & $2.3462]$ & \\
\hline$\alpha$ & \multicolumn{5}{|c|}{0.5826} & $\begin{array}{l}\text { Nonlinear 1st parameter, obtained by the integral of absolute error } \\
\text { (IAE) method }\end{array}$ \\
\hline$\beta$ & \multicolumn{5}{|c|}{1000} & $\begin{array}{l}\text { Nonlinear } 2 \text { nd parameter, obtained by setting desired damping } \\
\text { ratio of closed loop system }\end{array}$ \\
\hline$P$ & \multicolumn{5}{|c|}{ Diagonal $10 \times 10$} & Obtained based on Lyapunov as in equation \\
\hline
\end{tabular}

While, for CNF controller, it has two parts which are a linear feedback part and nonlinear feedback part. The objective of linear feedback is to get a small damping ratio for quick response and nonlinear feedback is designed to increase the damping ratio as the system output approaches the target reference to avoid overshoot [24, 25]. In this study, the target reference is zero.

The linear control law for torque of antiroll bar is defined as

$$
\begin{aligned}
& \mid T_{\mathrm{ARB}} \\
& =\text { Disturbance }-\left(K_{\mathrm{lqr}} K_{\mathrm{kalman}}+F x+G r\right. \\
& \left.+\rho(y, r) B^{T} P\left(x-x_{e}\right)\left[\begin{array}{c}
\phi \\
\dot{\phi}
\end{array}\right]\right) \mid,
\end{aligned}
$$

where

$$
\begin{gathered}
K_{\mathrm{lqr}}=R B^{T} P_{\mathrm{lqr}}, \quad K_{\mathrm{kalman}}=P_{f} C^{T} R_{f}^{-1}, \\
r=0, \quad \rho(y, r)=-\beta e^{-\alpha \alpha_{0}|y-r|}, \quad x_{e}=G_{r} r .
\end{gathered}
$$

The value of $P$ is obtained from Lyapunov method in (30).

Then, the states are

$$
x=\left[\begin{array}{llllllllll}
z_{s} & z_{u R} & z_{u L} & \dot{z}_{s} & \dot{z}_{u R} & \dot{z}_{u L} & \phi & \dot{\phi} & V_{y} & \dot{\psi}
\end{array}\right]^{T} .
$$

\subsection{Parameters Tuning for LQG and CNF Controller}

(1) Gain for LQR regulator: using Bryson's rule method

$$
Q=\operatorname{diag}\left[\begin{array}{ll}
\frac{1}{(0.09)^{2}} & \frac{1}{(0.09)^{2}}
\end{array}\right], \quad R=\frac{1}{3^{2}} \text {. }
$$

(2) Gain for LQG: using intuitive method

$$
Q_{f}=500, \quad R_{f}=\operatorname{diag}\left[\begin{array}{ll}
0.001 & 0.001
\end{array}\right] .
$$

(3) State feedback gain matrix $F$ gain in linear part of CNF controller obtained based to damping ratio, set at 0.67 and using the LQR tuning method. Firstly, the gain of LQR is tuned using intuitive method. Then, the variation of tuning is designed until the damping ratio is set at 0.67 in finding the gain value of a matrix $F$. The parameter $\alpha$ can be found by the integral of

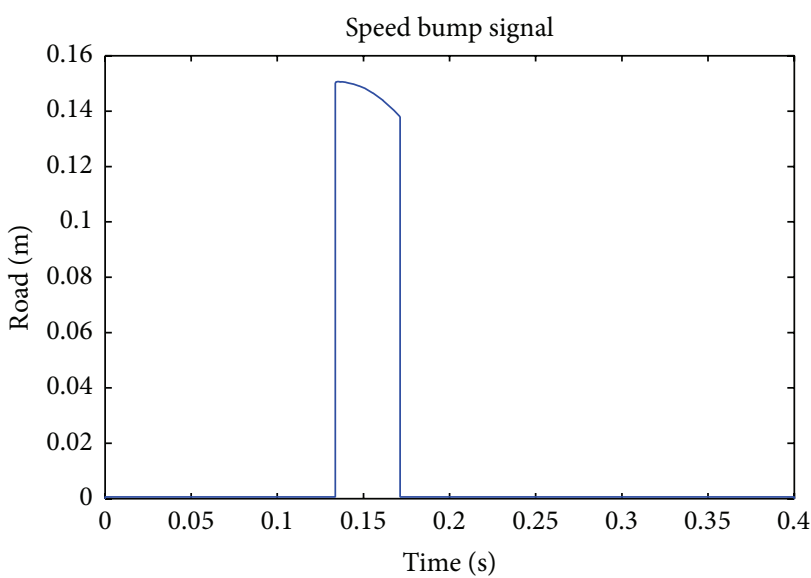

FIGURE 5: Speed bump signal.

absolute error (IAE) method. Meanwhile, an optimal $\beta$ is obtained by setting the desired damping ratio of closed loop system. Table 1 shows numerical parameters CNF controller obtained during these processes.

4.3. Simulation Results. Two patterns and level of cornering manoeuvres and road holding disturbance is considered to evaluate the performance of the designed controller. Besides, the comparison is performed by comparing LQG with LQG CNF fusion results. Three types of input disturbance patterns are used which are single sine, fishhook, and speed bump tests. Figures 5, 6, and 7 show three types of tests used.

The controllers are designed and tuned to realize their performance corresponding to a torque to reduce the body roll angle and body roll rate. Therefore, from these simulations, the vehicle that is using active ARB with LQG CNF fusion control strategy has a good ride and handling at the same time.

Moreover, to verify and investigate the effectiveness of the proposed control method, computer simulations based on Matlab software were conducted and the output responses of roll angle and roll rate are compared with output signal between the different control strategies.

4.4. Road Profiles. The characteristic of road disturbance that is made for the system is shown in Figure 5 and the road profile is speed bump signal with speed of $40 \mathrm{~km} / \mathrm{h}$ and frequency of $14.815 \mathrm{~Hz}$, and time delay required is $0.18 \mathrm{~s}$. 


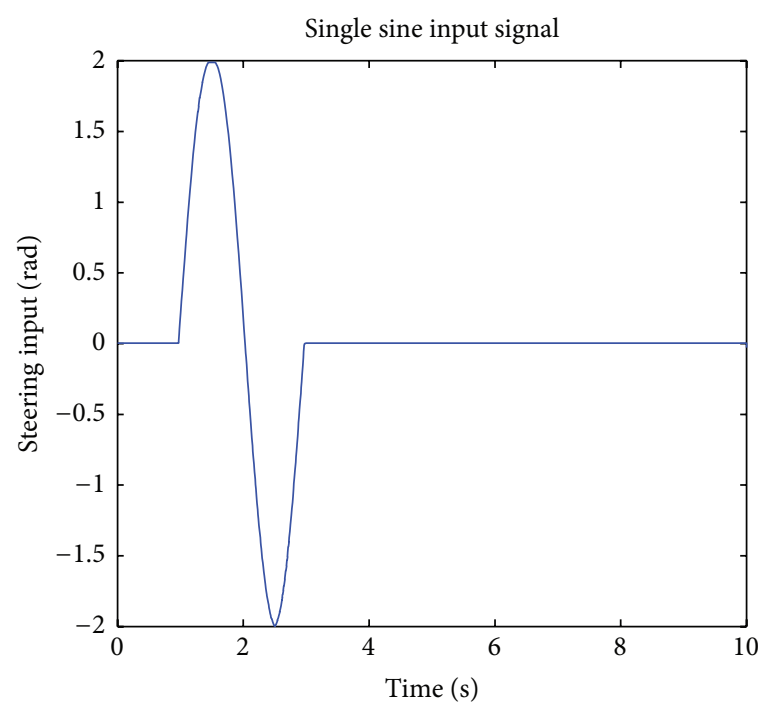

(a)

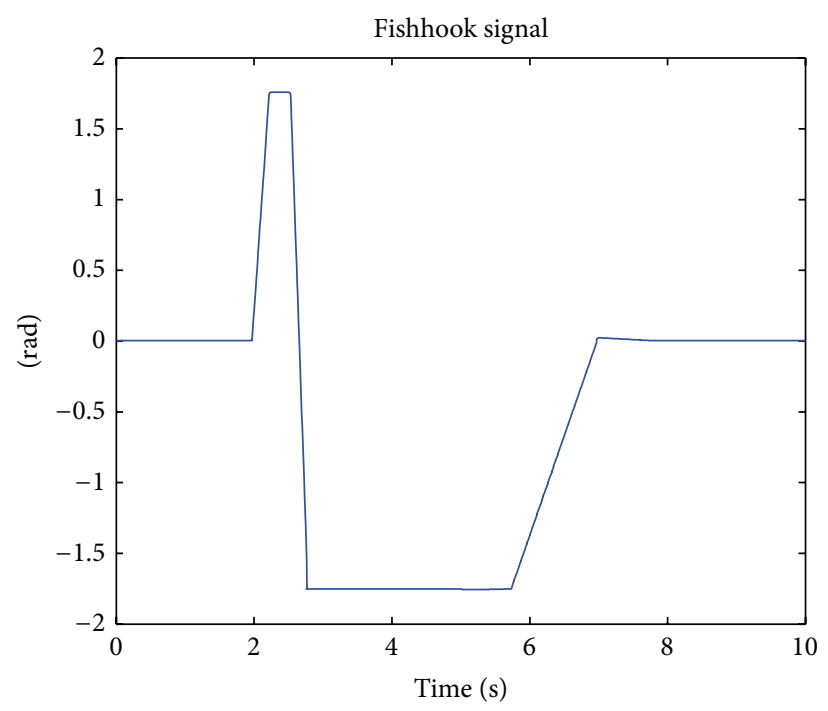

(b)

FiguRE 6: (a) Single sine input signal and (b) fishhook signal.

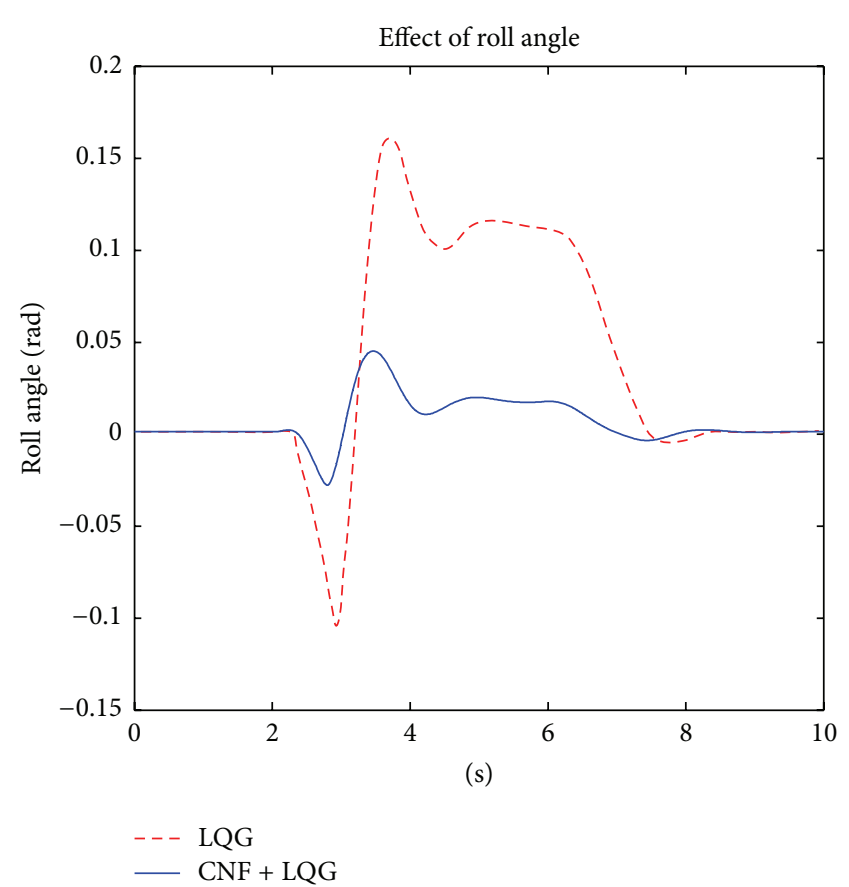

(a)

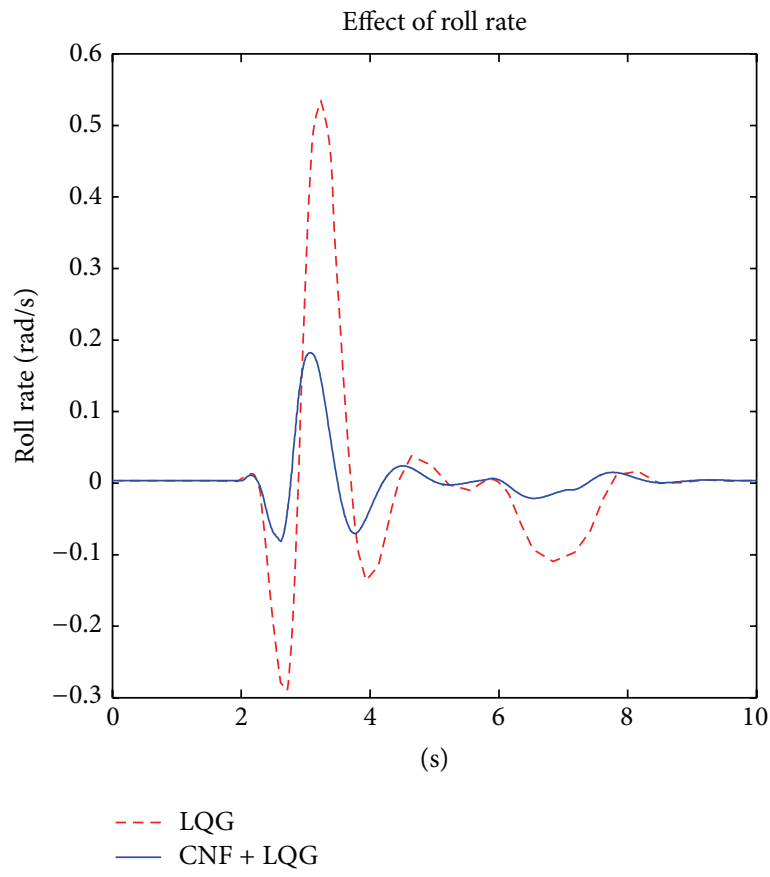

(b)

FIGURE 7: Fishhook test (a) roll angle response and (b) roll rate response.

4.5. Manoeuvres. Various patterns and levels of cornering manoeuvres are considered to evaluate the performances of roll angle and roll rate as well as the robustness of the controller design. Two types of pattern inputs are used, single sine input with an amplitude of $2 \mathrm{rad}$ and fishhook signal with amplitude of 1.755 rad. Figure 6 shows both types of steering inputs.

The trend indicates that further improvements in ride comfort and handling performance bring a similar pattern but the value of overshoot is dissimilar by using the different types of controller. Figures 7 and 8 show the signal responses for handling case while Figure 9 shows the signal performances for ride case. In handling case, it can be shown that an active ARB system using LQG controller is a very inferior quality while for the ride test also it is not as good as using a combination of LQG and CNF controllers.

Figures 7, 8, and 9 show the vehicle roll angle and roll rate response for the different tests which are fishhook, speed 


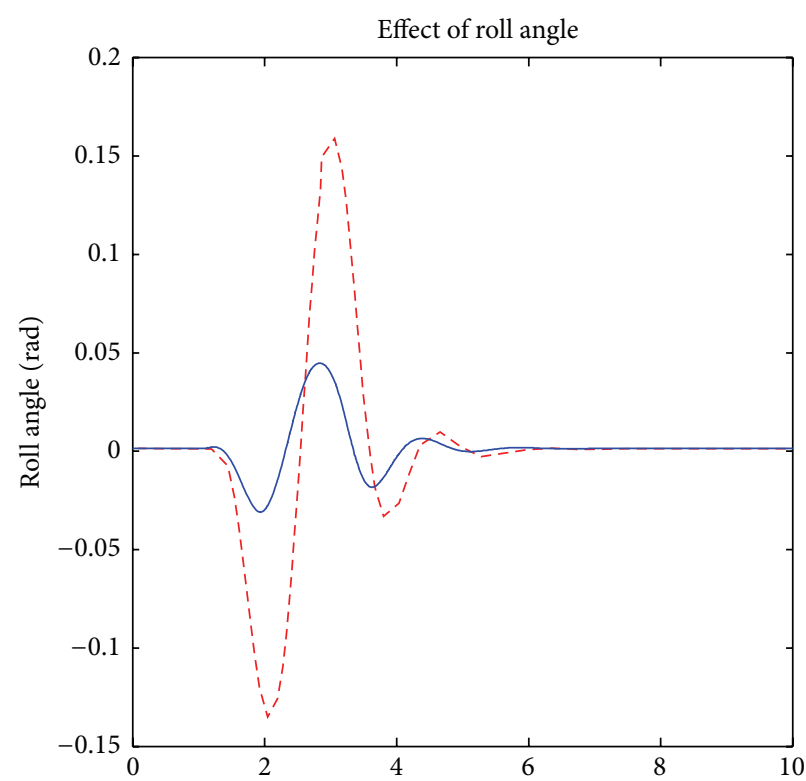

(s)

--- LQG

$-\mathrm{CNF}+\mathrm{LQG}$

(a)

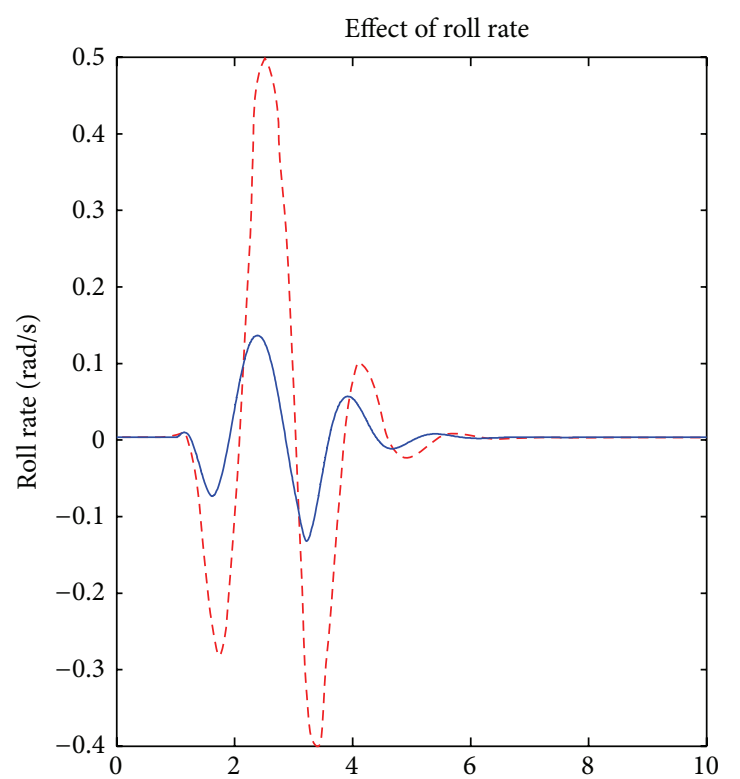

(s)

-- - LQG

$-\mathrm{CNF}+\mathrm{LQG}$

FIGURE 8: Single sine input test (a) roll angle response and (b) roll rate response.

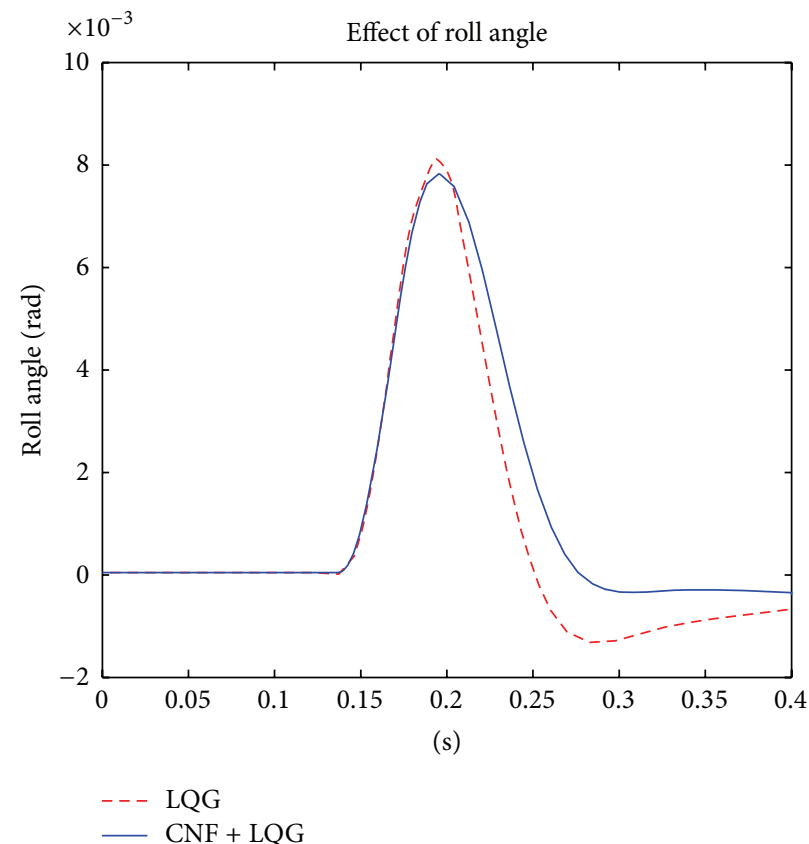

(a)

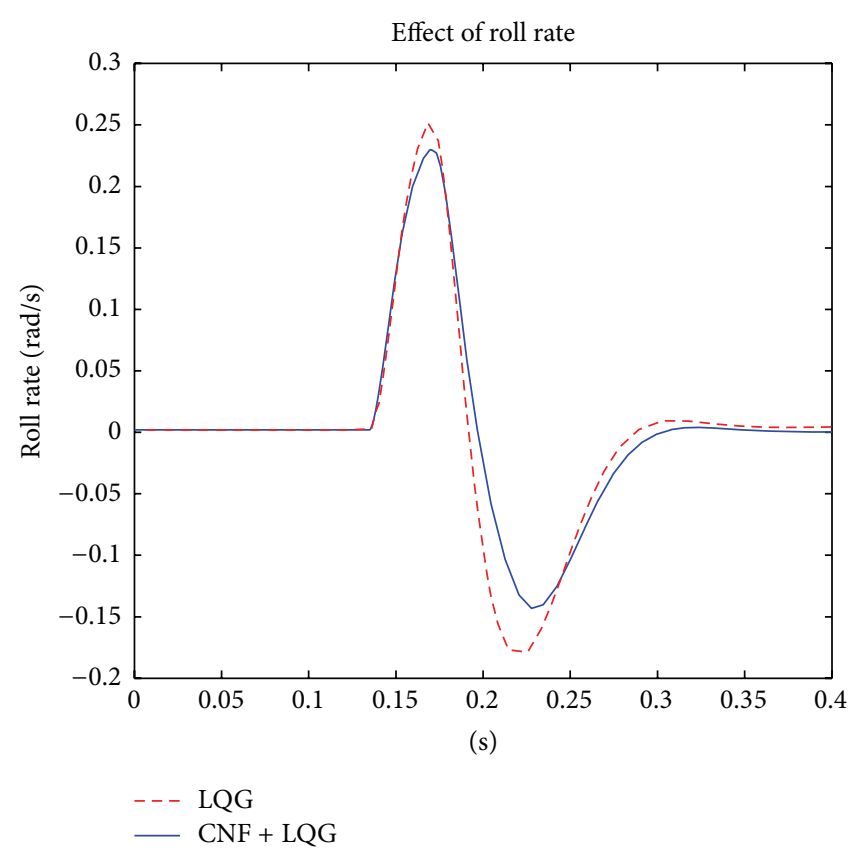

(b)

FIGURE 9: Speed bump test (a) roll angle response and (b) roll rate response.

bump, and single sine inputs. It can be seen in Figure 7 that the roll angle and roll rate response is highly reduced for an active ARB system that used LQG CNF fusion compared with LQG control strategy. The reduction of the body roll angle for LQG CNF fusion compared with LQG is about $74.2 \%$, whereas the roll rate improvement in this figure is approximately $66.7 \%$. For Figure 8, there was improvement in the maximum body roll angle between the systems with 


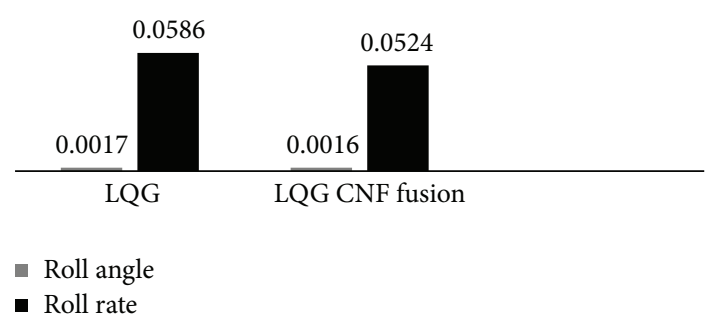

FIgURe 10: Speed bump test.

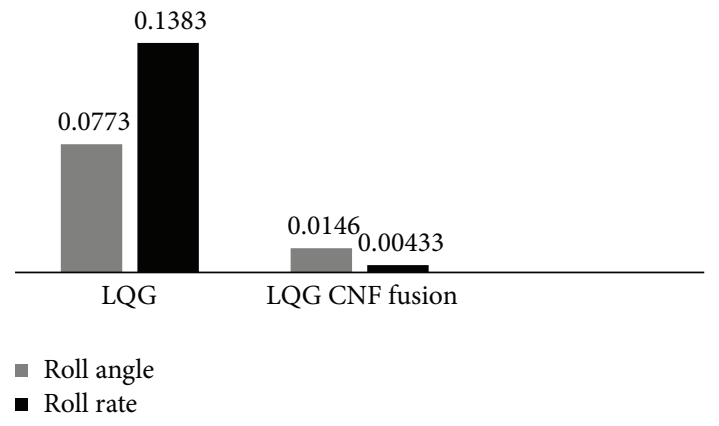

FIGURE 11: Fishhook test.

LQG CNF fusion control scheme and with LQG of 75\%, while for the body roll rate an improvement is around $72 \%$. Moreover, for Figure 9, the roll angle and roll rate responses are slightly reduced for the active ARB system that is used for LQG CNF fusion controller compared with LQG. The body roll angle is reduced about $4.9 \%$ while roll rate showed $11.54 \%$ improvement compared between LQG CNF fusion and LQG control strategy. Therefore, by using LQG CNF fusion control strategy, the performances of roll angle and roll rate in handling and ride test are better and the rollover of the vehicle is more decreased compared with the system connected to LQG. From these simulation results, the vehicles that used active ARB with CNF with LQG controller will reduce the trade-off gap between ride comforts and improve handling at the same time. From three tests conducted in this study, it can be shown that the performance by using an active ARB system with LQG combined with CNF controller seems better. The settling time is quicker and reduces the overshoot. The improvement of response signals is calculated by using the percentage reduction formula. The formula for percentage reduction is calculated as follows (see [3]):

$$
\% \text { reduction }=\frac{(\text { baseline_value }- \text { new_value })}{\text { baseline_value }} \times 100 \text {. }
$$

Figures 10, 11, and 12 show the numerical results of three different tests that compared between LQG and LQG CNF fusion control strategies. The RMS value for CNF with LQG controller is more decreased than LQG.

This section has presented simulation results of the proposed controllers and evaluation on the controller's performance in handling and ride performance. In order to verify the effectiveness and performance of designing controllers, various simulation tests have been carried out. Simulation

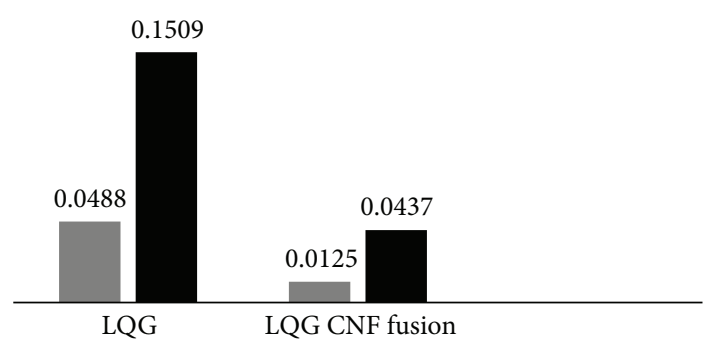

- Roll angle

- Roll rate

FIGURE 12: Single sine input test.

TABLE 2: Nominal CNF parameters.

\begin{tabular}{lc}
\hline Parameter & Value \\
\hline$\alpha$ & 1 \\
$\beta$ & 1000 \\
\hline
\end{tabular}

result shows that LQG CNF fusion control method is the best control strategy with fast response, lower settling time, reduced overshoot, and improved response of roll angle and roll rate.

4.6. Effect of Variation of CNF Parameters. The nominal parameters of the CNF controller are set as in Table 2 to investigate the influence of each parameter and then varied as follows. The test inputs in analysis of variation of CNF parameters are fishhook, single sine, and speed bump tests. The variation analysis for fishhook test is shown in Figures 13 and 14, whereas the variation analysis for single sine test is shown in Figures 15 and 16. In addition, the variation analysis for speed bump test is shown in Figures 17 and 18.

The value of $\alpha$ is varied from 1 to 10 in increment of 1 . The response for roll angle and roll rate has large overshoot as $\alpha$ is higher in magnitude. The variations in the responses as $\alpha$ varies are shown in Figure 13.

$\beta$ is varied from 1000 to 10000 in increment of 1000 . As shown in Figure 14, the responses get a lesser amount of overshoot as $\beta$ is larger in magnitude. As the nonlinear part controls how well the response is in terms of overshoots, it is expected that larger $\beta$ means better control and reduces the overshoot of the responses to fishhook test. The variations analysis for single sine test also has the same results as fishhook test. The results are shown in Figures 15 and 16. The settling times for roll angle and roll rate are decreased as $\beta$ is enlarged and the results are shown in Figures 14 and 16.

Moreover, the results of variation analysis for speed bump test are shown in Figures 17 and 18. As $\alpha$ increased, the roll angle and roll rate have a large magnitude of overshoot, while, as the value of $\beta$ increased, the responses to speed bump test also get larger overshoot and the settling time is decreased.

It can be concluded that the resulting performances have difference variations analysis between the ride comfort test and handling test. The difference of variation is for the value of $\beta$ only. For ride comfort test, $\beta$ must have lower value to 


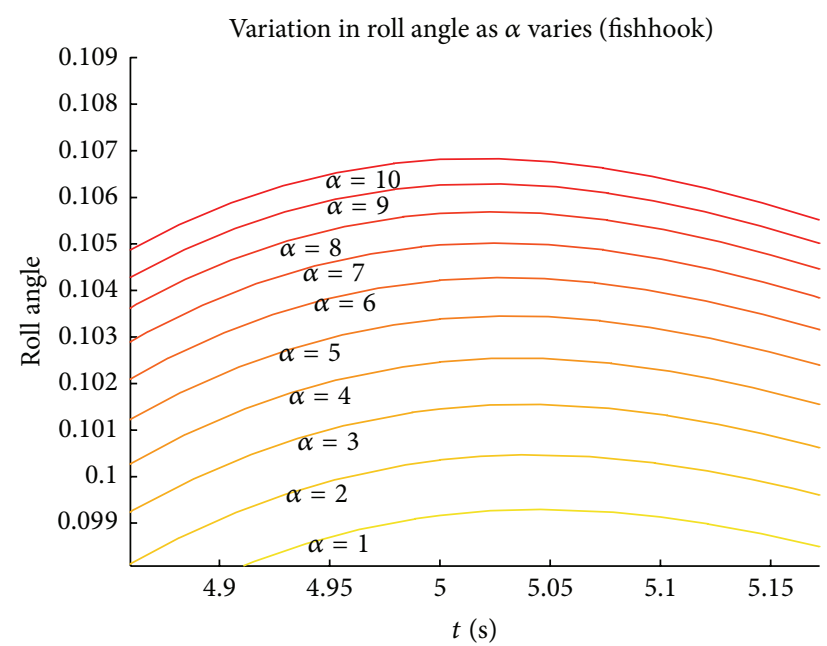

(a)

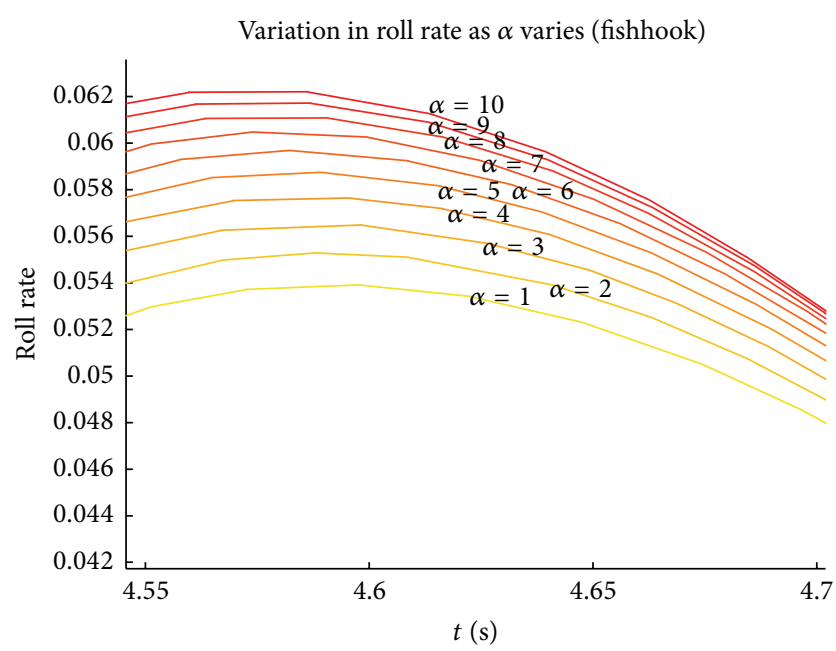

(b)

FIGURE 13: Fishhook: (a) variation in $\phi$ as $\alpha$ varies; (b) variation in $\dot{\phi}$ as $\alpha$ varies.

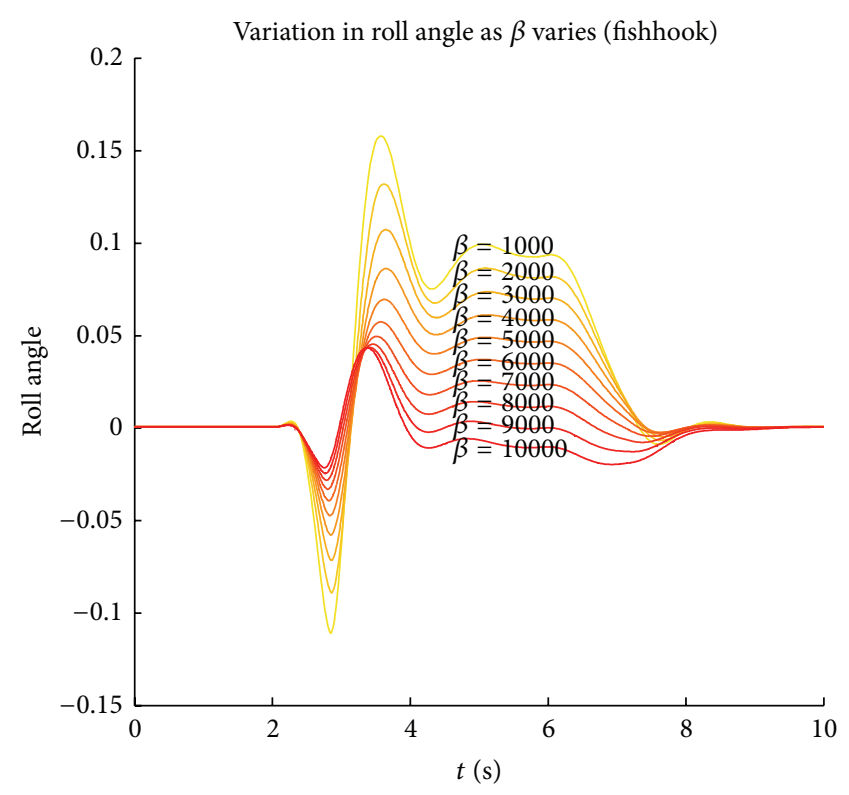

(a)

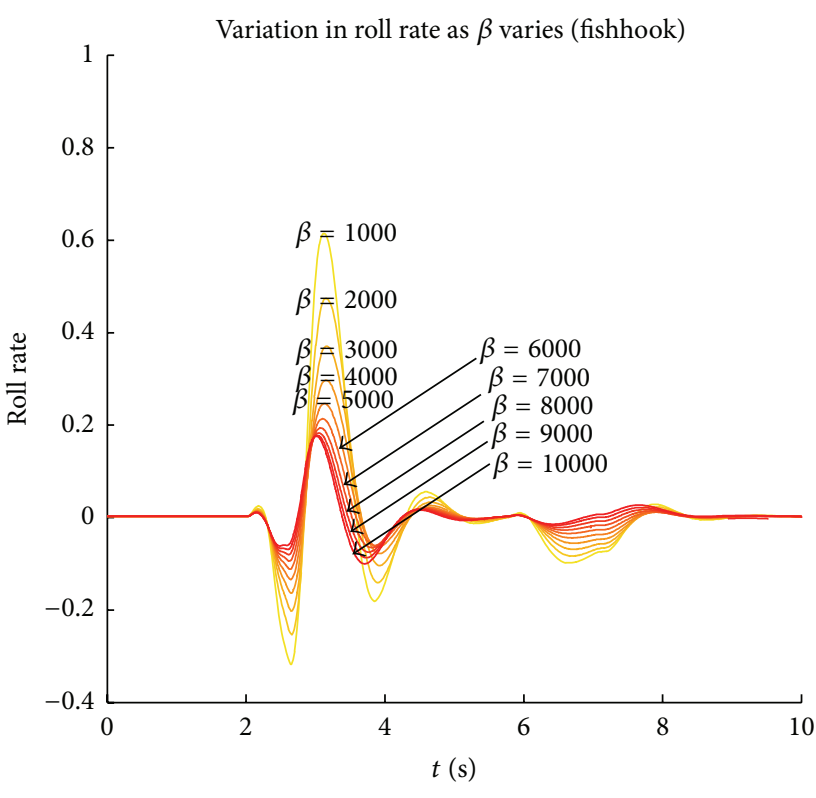

(b)

FIGURE 14: Fishhook: (a) variation in $\phi$ as $\beta$ varies; (b) variation in $\dot{\phi}$ as $\beta$ varies.

get less overshoot and fast settling time for roll angle and roll rate. At the same time for handling test, the value of $\beta$ needs to increase to get a reduced amount of overshoot and quick settling time for responses of roll angle and roll rate.

\section{Conclusions}

This paper compares the performance of different types of controllers which are the system with LQG and LQG CNF fusion control strategy. A four DOF vehicle model has been used to model the vehicle suspension system. The Matlab/SIMULINK environment of the simulation model on the antiroll designs for four DOF vehicle dynamic models is used to simulate the proposed control system of an active ARB and its counterparts. Based on the results, the performance of the proposed system is capable of achieving better performance than its counterparts in terms of roll angle and roll rate reduction during roll induced manoeuvre. For future work, more advanced control structure and control design will be investigated under various manoeuvres in order to improve the vehicle stability and this would not only benefit handling aspect of the vehicle but also contribute to vehicle ride comfort. The techniques of optimization also will be further studied to gain better performances. 


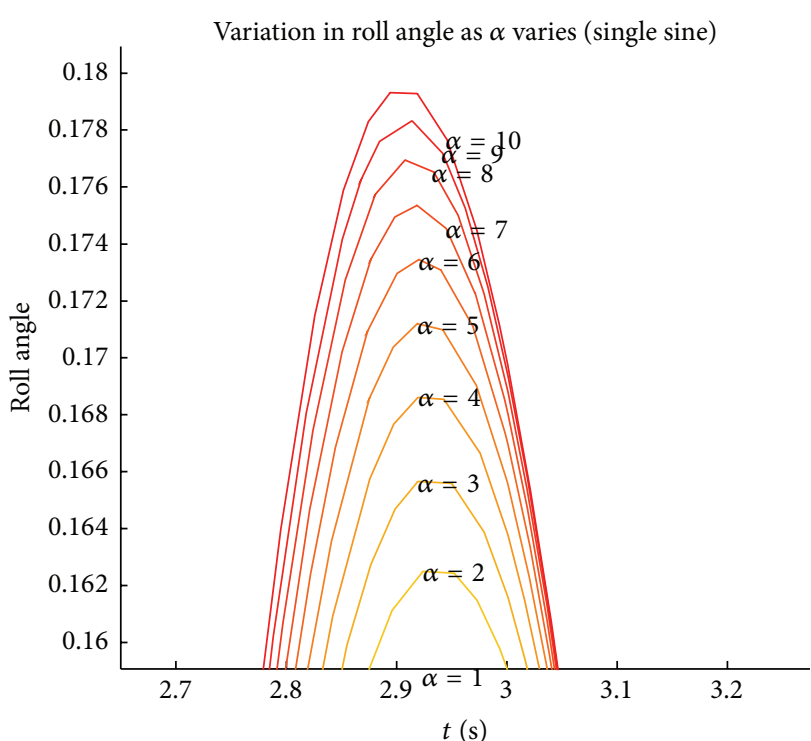

(a)

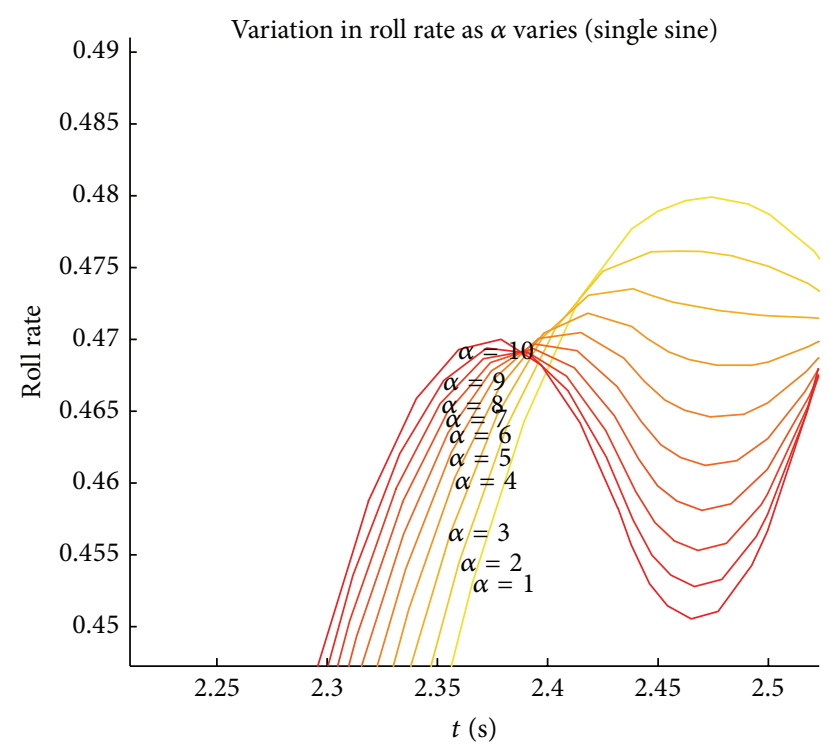

(b)

FIGURE 15: Single sine: (a) variation in $\phi$ as $\alpha$ varies; (b) variation in $\dot{\phi}$ as $\alpha$ varies.

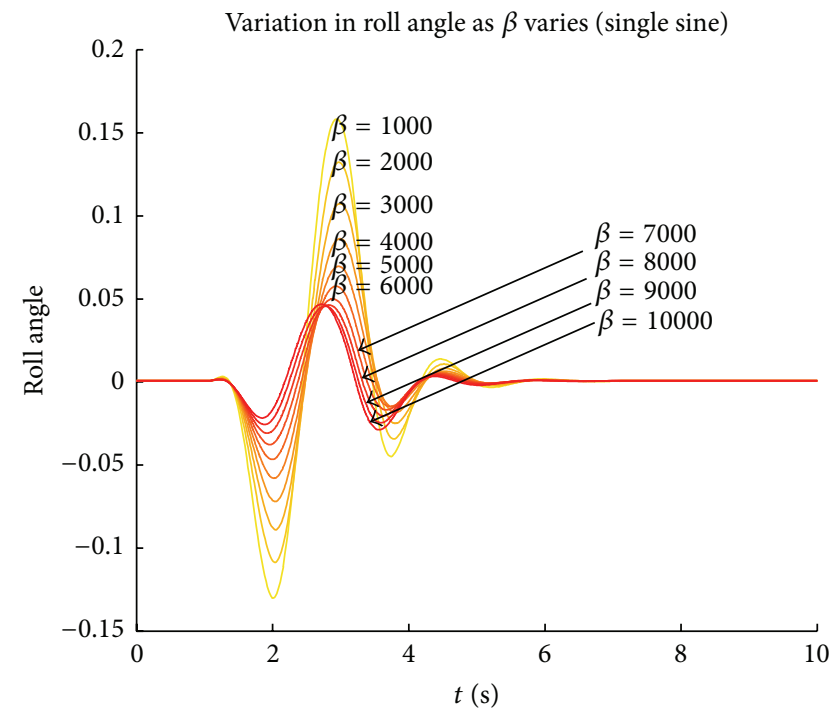

(a)

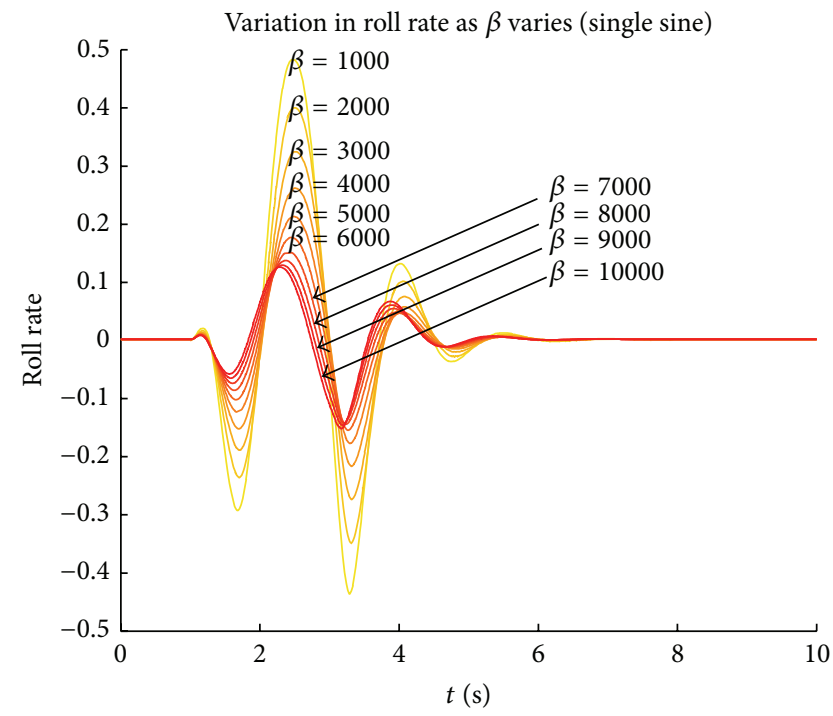

(b)

Figure 16: Single sine: (a) variation in $\phi$ as $\beta$ varies; (b) variation in $\dot{\phi}$ as $\beta$ varies.

\section{Nomenclatures of the Vehicle System}

$m_{s}: \quad$ Sprung mass weight

$m_{u L}$ : Left unsprung mass weight

$m_{u R}$ : Right unsprung mass weight

$z_{s}: \quad$ Body displacement

$\dot{z}_{s}:$ Body deflection

$z_{u L}:$ Left wheel displacement

$\dot{z}_{u L}$ : Left wheel deflection

$z_{u R}$ : Right wheel displacement

$\dot{z}_{u R}$ : Right wheel deflection

$\phi$ : $\quad$ Roll angle $\dot{\phi}: \quad$ Roll rate

$V_{y}$ : Lateral velocity

$b_{L}$ : Length for CG to the left wheel suspension

$b_{R}$ : Length for CG to the right wheel suspension

$c$ : Damping stiffness

$k$ : $\quad$ Spring stiffness

$k_{t L}:$ Left tire stiffness

$k_{t R}$ : Right tire stiffness

$\delta$ : Steering angle

$K_{q}$ : Spring coefficient 


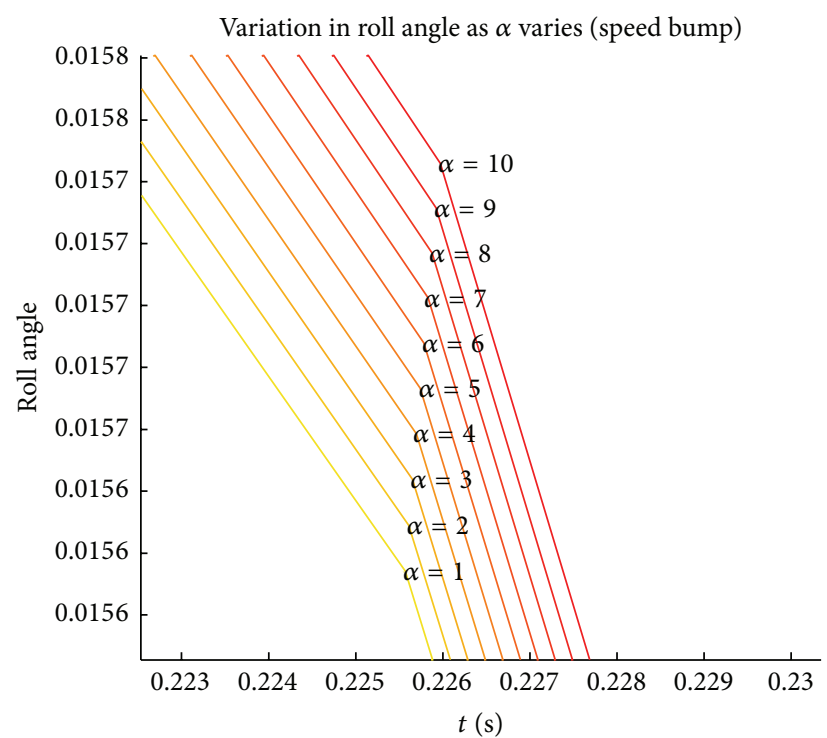

(a)

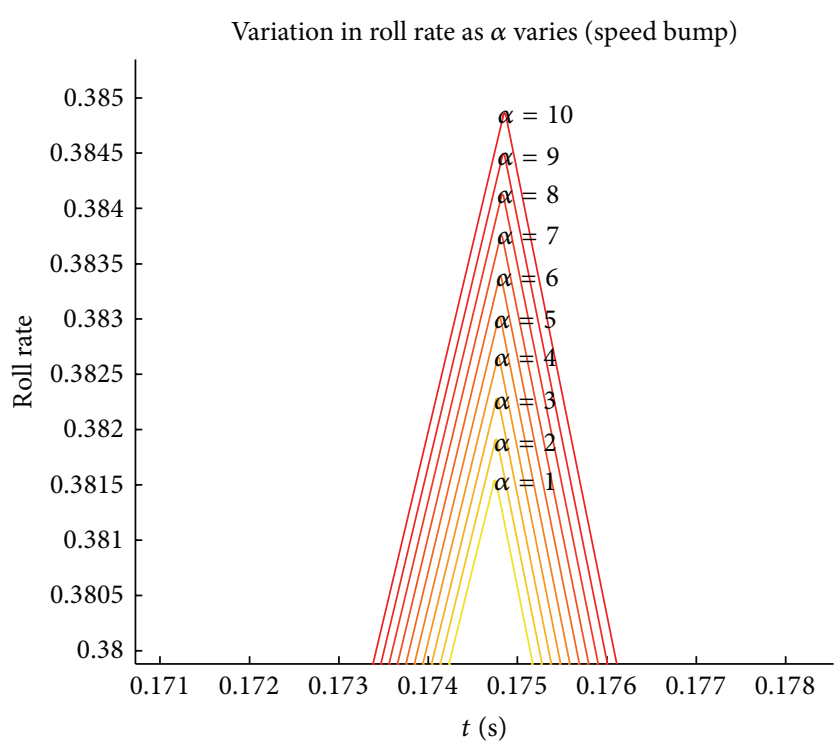

(b)

FIGURE 17: Speed bump: (a) variation in $\phi$ as $\alpha$ varies; (b) variation in $\dot{\phi}$ as $\alpha$ varies.

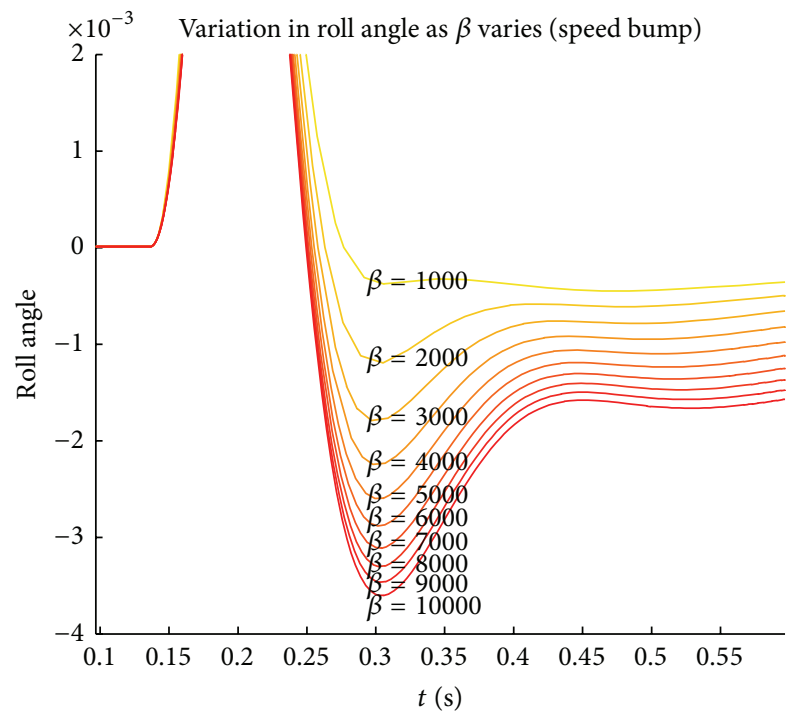

(a)

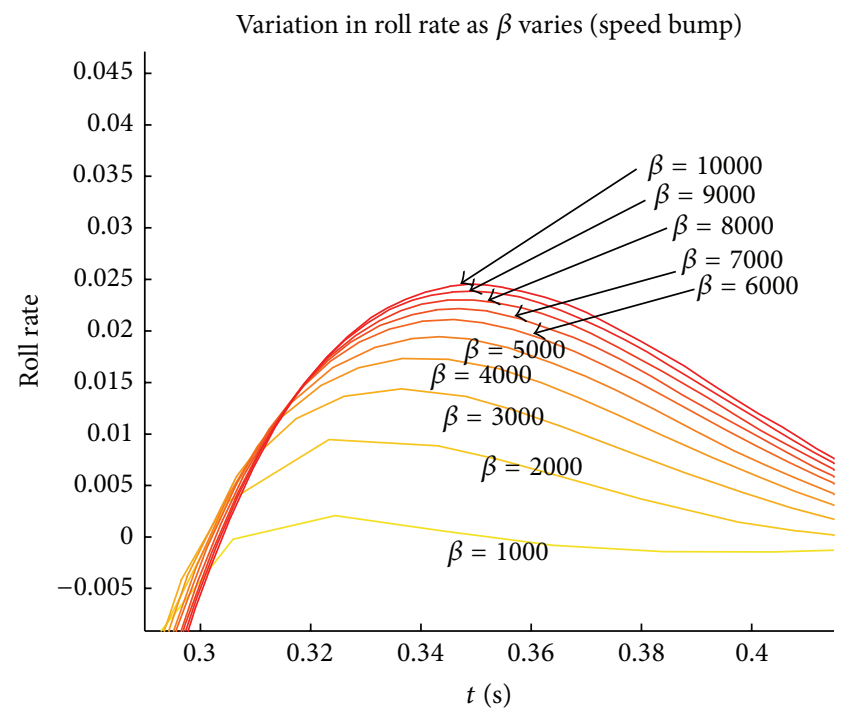

(b)

FIGURE 18: Speed bump: (a) variation in $\phi$ as $\beta$ varies; (b) variation in $\dot{\phi}$ as $\beta$ varies.

$K_{\mathrm{lqr}}:$ Gain of LQR regulator

$I_{s}: \quad$ Roll axis moment inertia

$F_{L}$ : Left suspension force

$F_{R}$ : Right suspension force

$k_{\mathrm{ARB}}$ : Antiroll bar stiffness

RC: Roll centre

$m$ : Mass of vehicle

$V_{x}$ : Longitudinal velocity

$C_{f}$ : Front cornering stiffness

$C_{r}$ : Rear cornering stiffness

$F_{y F}$ : Front lateral tire force

$F_{y R}:$ Rear lateral tire force
$I_{z z}: \quad$ Moment of inertia around the $z$-axis

$a$ : Distance from the front wheel to the centre of gravity

$b: \quad$ Distance from the rear wheel to the centre of gravity

$\dot{\psi}: \quad$ Yaw rate

$\alpha_{F}: \quad$ Slip angle of the front wheel

$\alpha_{R}: \quad$ Slip angle of the rear wheel

$h$ : Height

$C_{q}$ : Damping coefficient

$T_{\mathrm{ARB}}$ : Torque of antiroll bar

$K_{\text {kalman }}$ : Gain of Kalman filter. 


\section{Conflict of Interests}

The authors declare that there is no conflict of interests regarding the publication of this paper.

\section{Acknowledgments}

This work is fully supported by Ministry of Higher Education Malaysia and Universiti Teknologi Malaysia under FRGS research Grant (Vote no. 4F370) and research university Grant (Vote no. 00G64). The work is also supported by Proton Sdn. Bhd.

\section{References}

[1] H. Bayrakceken, S. Tasgetiren, and K. Aslantas, "Fracture of an automobile anti-roll bar," Engineering Failure Analysis, vol. 13, no. 5, pp. 732-738, 2006.

[2] N. Zulkarnain, F. Imaduddin, H. Zamzuri, and S. A. Mazlan, "Application of an Active Anti-roll bar system for enhancing vehicle ride and handling," in Proceedings of the IEEE Colloquium on Humanities, Science and Engineering Research (CHUSER '12), pp. 260-265, December 2012.

[3] International Standards Organisation, Mechanical Vibration and Shock-Evaluation of Human Exposure to Whole-Body Vibration, Part 1: General Requirements, ISO 2631-1, The International Organisation for Standardisation, 2nd edition, 1997.

[4] T. J. Yuen, R. Rahizar, Z. A. M. Azman, A. Anuar, and D. Afandi, "Design optimization of full vehicle suspension based on ride and handling performance," in Proceedings of the FISITA 2012 World Automotive Congress, vol. 195 of Lecture Notes in Electrical Engineering, pp. 75-86, 2013.

[5] C. Chumjun, C. Chantalakhana, and S. Koetniyom, "A compromise of comfort and handling in automotive vertical dynamics," in Proceedings of the 20th Conference of Mechanical Engineering Network of Thailand, Nakhon Ratchasima, Thailand, 2006.

[6] S. Yim, K. Jeon, and K. Yi, "An investigation into vehicle rollover prevention by coordinated control of active anti-roll bar and electronic stability program," International Journal of Control, Automation and Systems, vol. 10, no. 2, pp. 275-287, 2012.

[7] D. E. Williams and W. M. Haddad, "Active suspension control to improve vehicle ride and handling," Vehicle System Dynamics, vol. 28, no. 1, pp. 1-24, 1997.

[8] P. H. Cronjé and P. S. Els, "Improving off-road vehicle handling using an active anti-roll bar," Journal of Terramechanics, vol. 47, no. 3, pp. 179-189, 2010.

[9] D. Danesin, P. Krief, A. Sorniotti, and M. Velardocchia, "Active roll control to increase handling and comfort," Journal of Passenger Cars, Mechanical Systems, vol.112, no. 6, pp. 1007-1017, 2003.

[10] K. Yamamoto and H. Nishimura, "Control system design of electric power steering for a full vehicle model with active stabilizer," Journal of System Design and Dynamics, vol. 5, no. 5, pp. 789-804, 2011.

[11] S. Buma, Y. Ookuma, A. Taneda, K. Suzuki, J. S. Cho, and M. Kobayashi, "Design and development of electric active stabilizer suspension system," Journal of System Design and Dynamics, vol. 4, no. 1, pp. 61-76, 2010.

[12] Y. Ohta, H. Kato, D. Yamada et al., "Development of an electric active stabilizer system based on robust design," SAE Technical Paper 2032, 251, 2006.
[13] B. M. Chen, T. H. Lee, K. Peng, and V. Venkataramanan, "Composite nonlinear feedback control for linear systems with input saturation: theory and an application," IEEE Transactions on Automatic Control, vol. 48, no. 3, pp. 427-439, 2003.

[14] B. M. Chen, T. H. Lee, K. Peng, and V. Venkataramanan, Hard Disk Drive Servo Systems, Springer, London, UK, 2nd edition, 2006.

[15] G. Cheng, K. Peng, B. M. Chen, and T. H. Lee, "Improving transient performance in tracking general references using composite nonlinear feedback control and its application to high-speed XY-table positioning mechanism," IEEE Transactions on Industrial Electronics, vol. 54, no. 2, pp. 1039-1051, 2007.

[16] S. Gosselin-Brisson, M. Bouazara, and M. J. Richard, "Design of an active anti-roll bar for off-road vehicles," Shock and Vibration, vol. 16, no. 2, pp. 155-174, 2009.

[17] H. B. Pacejka, Tyre and Vehice Dynamics, ButterworthHeinemann, Oxford, UK, 2002.

[18] D. Fischer and R. Isermann, "Mechatronic semi-active and active vehicle suspensions," Control Engineering Practice, vol. 12, no. 11, pp. 1353-1367, 2004.

[19] M. F. Ismail, K. Peng, N. Hamzah, Y. M. Sam, M. K. Aripin, and M. H. Che Hasan, "A linear model of quarter car active suspension system using composite nonlinear feedback control," in Proceeding of the IEEE Student Conference on Research and Development (SCOReD '12), pp. 98-103, Pinang, Malaysia, December 2012.

[20] M. F. Ismail, K. Peng, N. Hamzah, Y. M. Sam, and M. K. Aripin, "A control performance of linear model and the MacPherson model for active suspension system using composite nonlinear feedback," in Proceedings of the IEEE International Conference on Control System, Computing and Engineering (ICCSCE '12), pp. 227-233, Penang, Malaysia, November 2012.

[21] Y. M. Sam, M. R. H. A. Ghani, and N. Ahmad, "LQR controller for active car suspension," in TENCON 2000. Proceedings, vol. 1, pp. 441-444, Kuala Lumpur, Malaysia, September 2000.

[22] W. Lan, B. M. Chen, and Y. He, "Composite nonlinear feedback control for a class of nonlinear systems with input saturation," in IFAC World Congress, Prague, Czech, July 2005.

[23] D. Gu and H. Hu, "Neural predictive control for a car-like mobile robot," Robotics and Autonomous Systems, vol. 39, no. 2, pp. 73-86, 2002.

[24] S. A. Saruchi, H. Zamzuri, S. A. Mazlan, S. M. H. Fahami, and N. Zulkarnain, "Wheel synchronization control in steer-by-wire using composite nonlinear feedback," Applied Mechanics and Materials, vol. 575, pp. 762-765, 2014.

[25] N. Zulkarnain, H. Zamzuri, and S. A. Mazlan, "Combined CNF with LQR in improving ride and handling for ground vehicle," Applied Mechanics and Materials, vol. 575, pp. 749-752, 2014. 


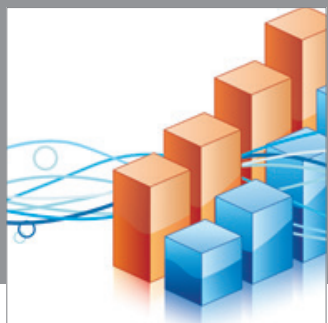

Advances in

Operations Research

mansans

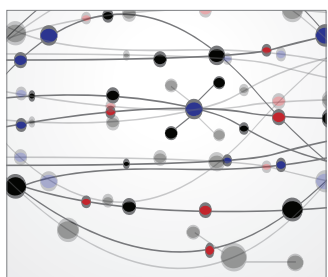

The Scientific World Journal
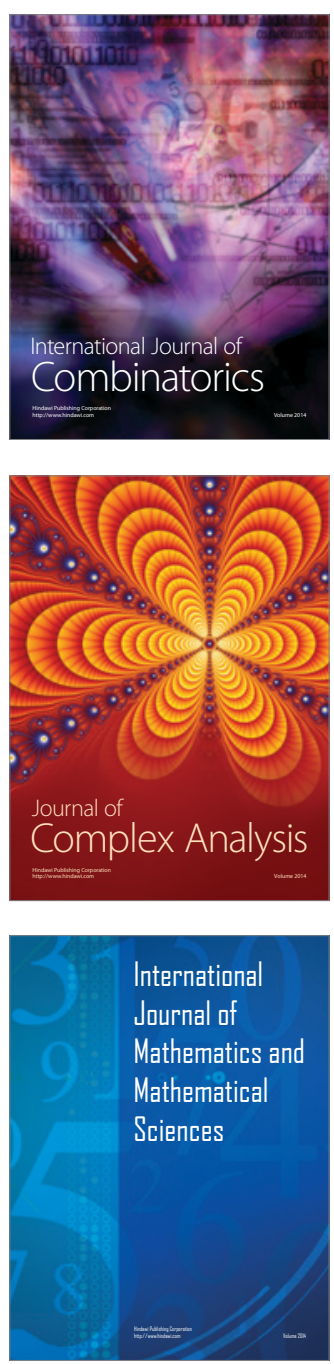
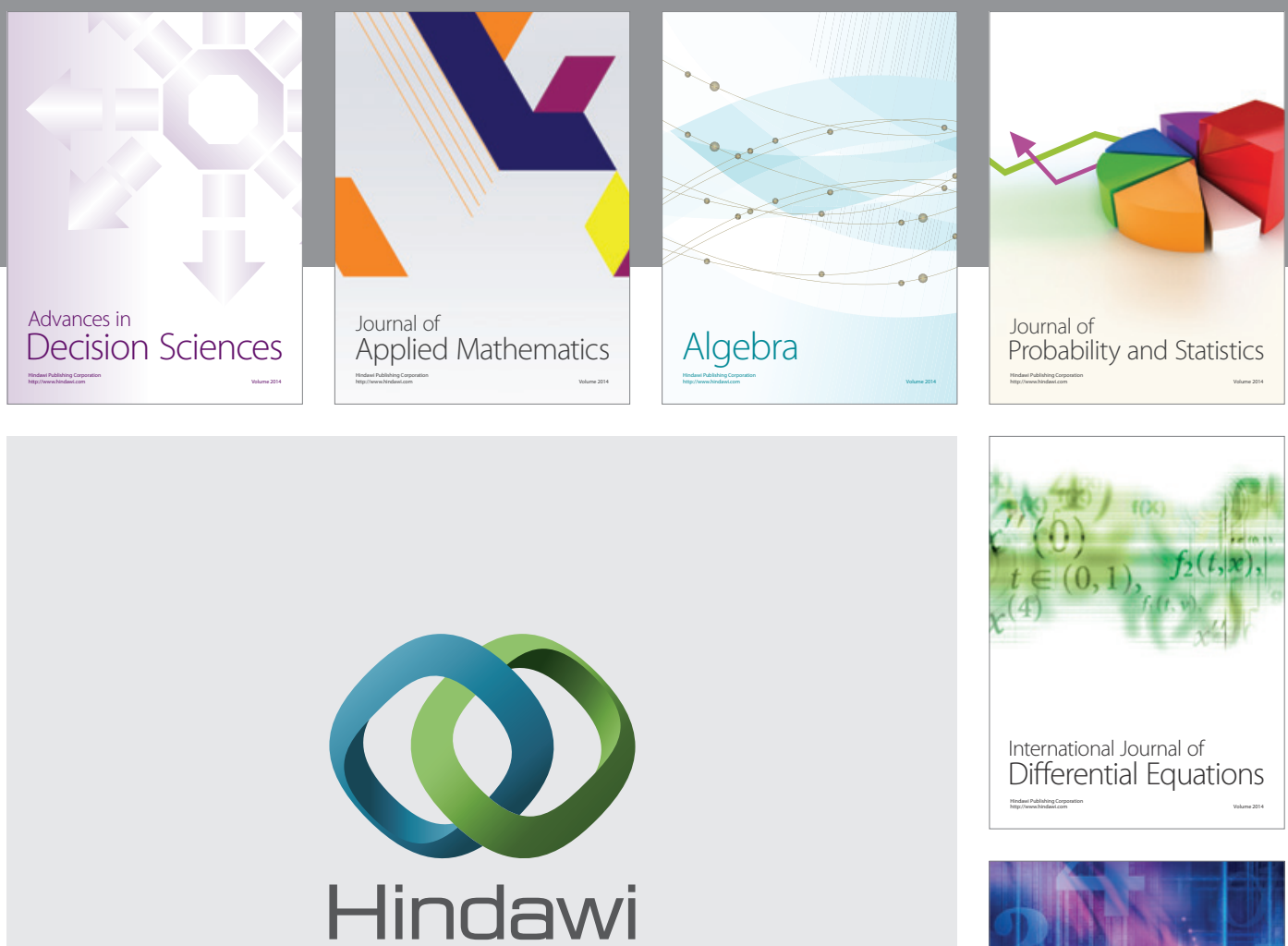

Submit your manuscripts at http://www.hindawi.com
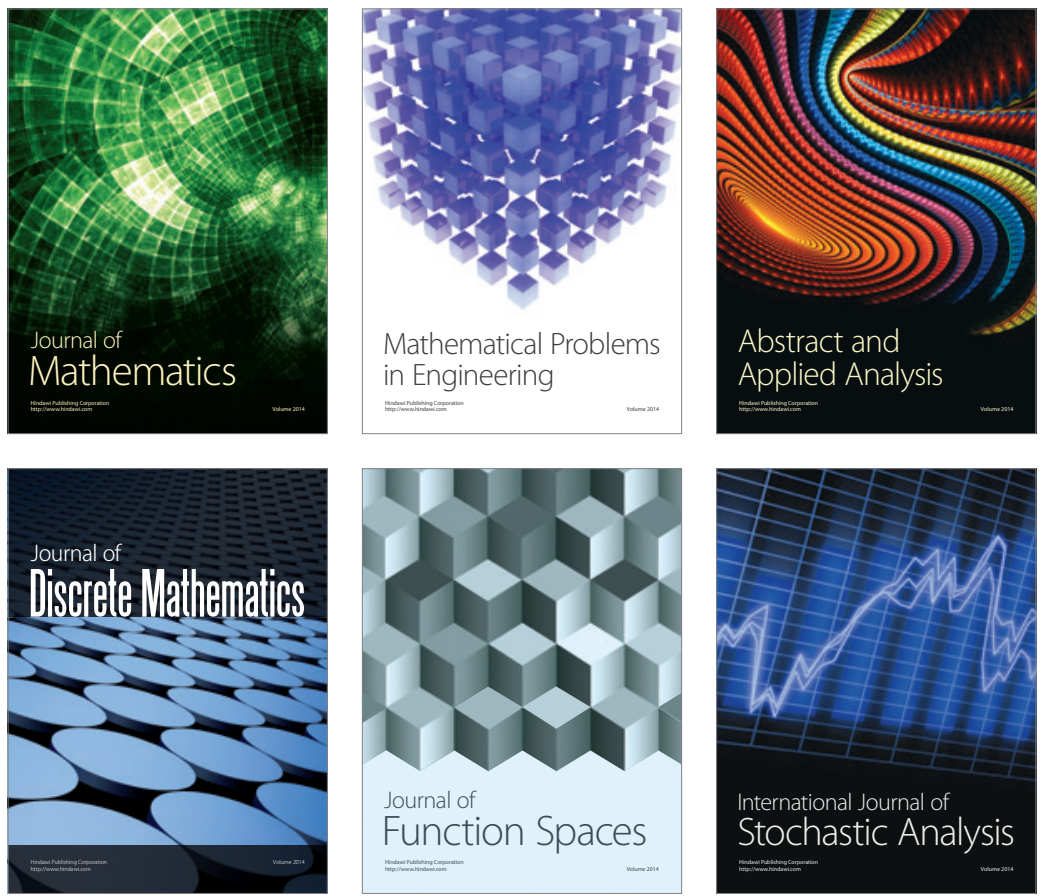

Journal of

Function Spaces

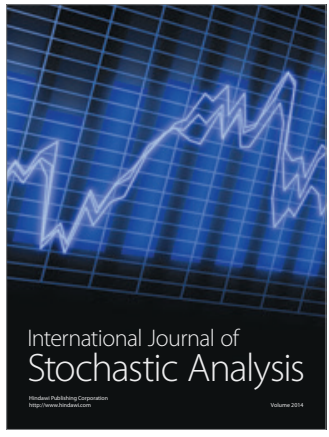

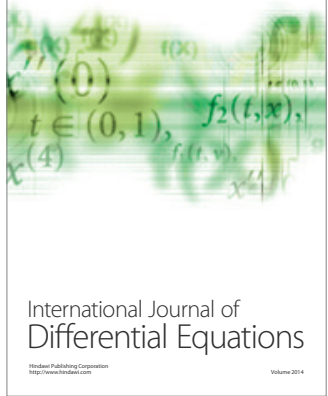
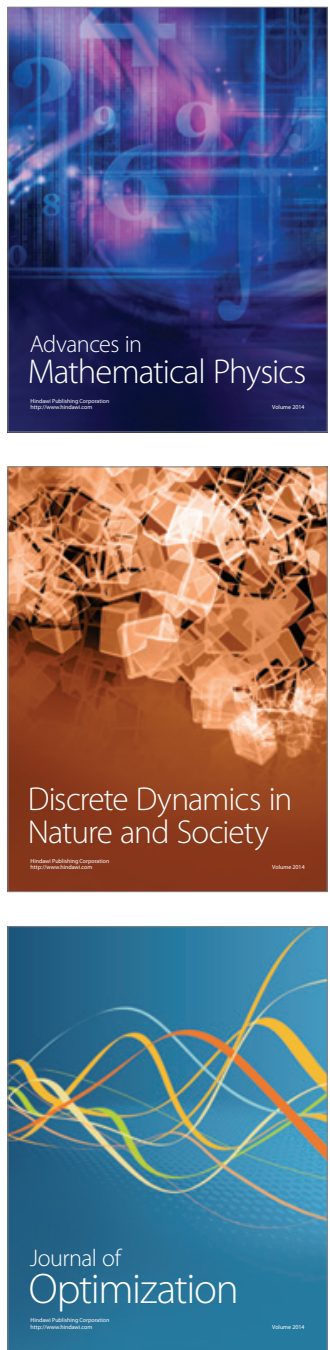